\title{
Evaluating the ecology of Spinosaurus: Shoreline generalist or aquatic pursuit specialist?
}

\author{
David W.E. Hone and Thomas R. Holtz, Jr.
}

\begin{abstract}
The giant theropod Spinosaurus was an unusual animal and highly derived in many ways, and interpretations of its ecology remain controversial. Recent papers have added considerable knowledge of the anatomy of the genus with the discovery of a new and much more complete specimen, but this has also brought new and dramatic interpretations of its ecology as a highly specialised semi-aquatic animal that actively pursued aquatic prey. Here we assess the arguments about the functional morphology of this animal and the available data on its ecology and possible habits in the light of these new finds. We conclude that based on the available data, the degree of adaptations for aquatic life are questionable, other interpretations for the tail fin and other features are supported (e.g., socio-sexual signalling), and the pursuit predation hypothesis for Spinosaurus as a "highly specialized aquatic predator" is not supported. In contrast, a 'wading' model for an animal that predominantly fished from shorelines or within shallow waters is not contradicted by any line of evidence and is well supported. Spinosaurus almost certainly fed primarily from the water and may have swum, but there is no evidence that it was a specialised aquatic pursuit predator.
\end{abstract}

David W.E. Hone. Queen Mary University of London, Mile End Road, London, E1 4NS, UK. d.hone@qmul.ac.uk

Thomas R. Holtz, Jr. Department of Geology, University of Maryland, College Park, Maryland 20742 USA and Department of Paleobiology, National Museum of Natural History, Washington, DC 20560 USA. tholtz@umd.edu

Keywords: behaviour; paleoecology; Theropoda; Spinosauridae; semi-aquatic

Submission: 15 July 2020. Acceptance: 7 January 2021.

Hone, David W.E. and Holtz, Thomas R., Jr. 2021. Evaluating the ecology of Spinosaurus: Shoreline generalist or aquatic pursuit specialist? Palaeontologia Electronica, 24(1):a03. https://doi.org/10.26879/1110

palaeo-electronica.org/content/2021/3219-the-ecology-of-spinosaurus

Copyright: January 2021 Paleontological Society.

This is an open access article distributed under the terms of Attribution-NonCommercial-ShareAlike 4.0 International (CC BY-NC-SA

4.0), which permits users to copy and redistribute the material in any medium or format, provided it is not used for commercial

purposes and the original author and source are credited, with indications if any changes are made.

creativecommons.org/licenses/by-nc-sa/4.0/ 


\section{INTRODUCTION}

Since its discovery and description (Stromer, 1915) the spinosaurine theropod Spinosaurus has been the subject of considerable discussion and debate as to its basic biology and ecology, a condition hampered by its fragmentary nature and the destruction of the holotype material during World War II (Smith et al., 2006). The fossil record of spinosaurids as a whole remains poor, with numerous fragmentary specimens (e.g., Stromer, 1915; Sues et al., 2002; Allain et al., 2012) and important records of some being based solely on teeth (Hone et al., 2010; Buffetaut, 2012). This is despite a record that spans well over 50 million years and with numerous specimens from Asia, Africa, Europe and South America (Hone and Holtz, 2017). Spinosaurids were unusual animals compared to other large carnivorous theropods (Holtz et al., 2004; Hone and Holtz, 2017), and Spinosaurus itself was potentially quite unusual even compared to its kin.

The spinosaurids are widely regarded as being at least partly piscivorous, and with potential affinities for aquatic habitats (e.g., Charig and Milner, 1995; Bertin, 2010; Cuff and Rayfield, 2013; Hone and Holtz, 2017; Aureliano et al., 2018; Hassler et al., 2018) although this does not exclude other prey or the occupation of other habitats (Bertin, 2010; Amiot et al., 2010a, b; Allain et al., 2012; Hendrickx et al., 2016), and likely took prey from the margins of aquatic habitats. The recent discovery of new and much more complete material has brought new data and with it new hypotheses about the biology of this animal (Ibrahim et al., 2014a, 2020a). Based on new finds, it has more recently been suggested that Spinosaurus was an aquatic specialist (Ibrahim et al., 2014a, 2020a, Arden et al., 2019; Beevor et al., 2020) and pursuit predator of aquatic prey (Ibrahim et al., 2020a). This stands in stark contrast to previous interpretations of spinosaurid biology and, if correct, would mark out Spinosaurus (and potentially other spinosaurines) as having a unique ecology for a nonavialian theropod. While these two general concepts-hereafter referred to as the 'wading model' and 'pursuit predator model'-have aspects in common (piscivory, affinities for water) they also differ dramatically in terms of the importance and engagement with aquatic vs terrestrial environments and locomotory adaptations.

\section{'Wading Model'}

This hypothesis considers spinosaurids as animals that primarily exploited riparian and similar habitats at the margins of aquatic environments (Paul, 1988; Holtz, 1998; Hone and Holtz, 2017; Henderson, 2018). They would be generalists of some form that in addition to foraging for fish or other aquatic prey from the shorelines, they could take prey on land, and even use their forelimbs to dig for buried items (e.g., lungfish). A number of lines of evidence support these contentions in addition to more general data showing they had affinities for aquatic environments and jaws well suited to capturing prey such as fish (e.g., see Charig and Milner, 1998). Spinosaurids are known to have had a diverse diet including fish, dinosaurs, and pterosaurs (Allain et al., 2012); they have a crocodile-like skull but one that notably does not have dorsally elevated nostrils or orbits (Hone and Holtz, 2019); isotopic data suggests that they foraged in aquatic systems but could also spend extended periods in terrestrial ecosystems (Amiot et al., 2010a, b). Where spinosaurids are present large numbers of specimens are often found, despite being otherwise generally rare, suggesting they are exploiting resources in a way other theropods cannot and may have been moving between patchy resources (Hone and Holtz, 2017).

These could be described as semi-aquatic since this term covers a huge range of behavior and degrees of aquatic adaptation (see Hone and Holtz, 2019). In short, these animals acted like large herons or storks (e.g., see Kushlan, 1976), taking fish and other aquatic prey from the edges of water or in shallow water, but also foraging for terrestrial prey and scavenging on occasion. Paul (1988) similarly argued that spinosaurids had a life habit that included fishing as well as terrestrial prey and carrion, noting that there are no large extant terrestrial animals that survive by fishing alone. While not explicitly stated before, swimming would potentially fit within this broadly riparian feeding model since it is suggested that they might need to regularly move between resource patches (Holtz et al., 2004).

\section{'Pursuit Predator Model'}

This model essentially advocates that Spinosaurus was "an active and highly specialized aquatic predator that pursued and caught its prey in the water column" (Ibrahim et al., 2020a, p3). There is no universal definition of pursuit-predation in the literature and it has been used for marine reptiles (e.g., ichthyosaurs, Massare, 1994), birds (peregrine falcons - Falco peregrinus, Cresswell and Qunn, 2013) and terrestrial mammals (hyenas - Crocuta crocuta, and cheetahs - Acinonyx juba- 
tus, Bro-Jørgensen, 2013) to relate to fast animals that pursue agile prey over a distance. Evidence presented to support this model was the pachyostotic skeleton, interlocking teeth, snout sensory system, tail adapted for swimming, dorsally positioned orbits and nares, reduced hind limbs, enlarged and possibly webbed toes and flat unguals (Ibrahim et al., 2014a, 2020a; Arden et al., 2019). Spinosaurus is described as semi-aquatic and inferred to have been occupying a similar niche to crocodilians (Arden et al., 2018). This considers Spinosaurus to be an animal highly adapted to life in water, with perhaps a reduced terrestrial capacity (Ibrahim et al., 2014).

\section{Interpreting Ecology}

While the pursuit predator model is focused on Spinosaurus (but could also potentially relate to other spinosaurines) the wading model applies more generally to all spinosaurids. The latter encompasses Spinosaurus, though we recognise that it does have unique anatomical features, and it (and other spinosaurines) may be more specialised in some areas than the baryonychines. This is similar to, for example, crocodiles, alligators, gharials and caimans that have much in common anatomically and ecologically, while also having different foraging and locomotory specialisations (e.g., Erickson et al., 2012). At present, no other member of Spinosaurinae is known from as complete material as is Spinosaurus, so some of the lines of evidence used to support this genus as being particularly aquatic may be found to be distributed more widely.

Here we assess the evidence for the competing hypotheses and the ecology of Spinosaurus (Figure 1). We follow the recommendations of Hone and Faulkes (2014) in trying to reconstruct the behaviour of extinct animals based on evaluating multiple lines of evidence to arrive at a holistic answer that as far as possible assesses all of the available data and arguments in the literature.

\section{Note on the Taxonomy of Spinosaurus}

The taxonomy of Spinosaurus in North Africa is somewhat controversial and has undergone a number of revisions over the years with various putative species or genera split or synonymised by various authors (e.g., see Holtz et al., 2004; Ibrahim et al., 2014, 2020b; Evers et al., 2015; Hendrickx et al., 2016; Hone andand Holtz, 2017). That most specimens are fragmentary and often nonoverlapping (and the destruction of the original holotype - Smith et al., 2006) however, means that uncertainties remain over the exact identities of various specimens. The most recent revision is by Ibrahim et al. (2020b) essentially grouped together various isolated spinosaurine pieces and putative different species, and the genus Sigilmassasaurus, under Spinosaurus aegyptiacus (see also Smyth et al., 2020). Although we do not agree with this designation, through the following manuscript we do work under the assumption that all the new material described in Ibrahim et al. (2024, 2020a) does relate to S. aegyptiacus sensu Stromer (1914) as does the Dal Sasso et al. (2005) skull.

\section{METHODS}

To evaluate several hypotheses and arguments made for both models, we assessed a number of features of the skull and postcranium of Spinosaurus in comparison to other non-avialan sauropsid reptiles of varying habits. We include both extant and extinct reptiles from numerous lineages of varying ecology-fundamentally terrestrial, semi-aquatic, and fully aquatic.

We note that the skull of Spinosaurus is not dorsally flattened in contrast to crocodylians and some other aquatic and semi-aquatic reptile lineages. To assess this we compiled a dataset (Appendix 1) of skull length, width and height for various taxa (extant and extinct). Length was measured from the tip of the snout to the occipital condyle in all cases, except theropods where the posterior measurement ran to the articular. The height of the skull did not include cranial ornamentation such as lacrimal horns, nor did it include the large palatal extensions of many crocodylians.

The naris and orbits of Spinosaurus have been regarded as being similarly positioned to those of aquatic and semi aquatic taxa (Arden et al., 2019) and are close to the dorsal margin of the skull so that the animal can breathe and see while remaining submerged. However, some semiaquatic and aquatic taxa have posteriorly positioned nares (e.g., phytosaurs) so we measured both the minimum distance of any part of the bony naris to the anterior margin and the dorsal of the skull. We also measured the orbit to the nearest dorsal margin (here including ornaments) to represent how much of the skull would need to be exposed for the animal to breathe or see above the surface.

These data (skull length, width, height, naris to anterior and dorsal margins and orbit to dorsal margin) were analysed with a Principal Components Analysis. However, the length of the skull (which varied from $22 \mathrm{~mm}$ to $2 \mathrm{~m}$ ) completely dom- 

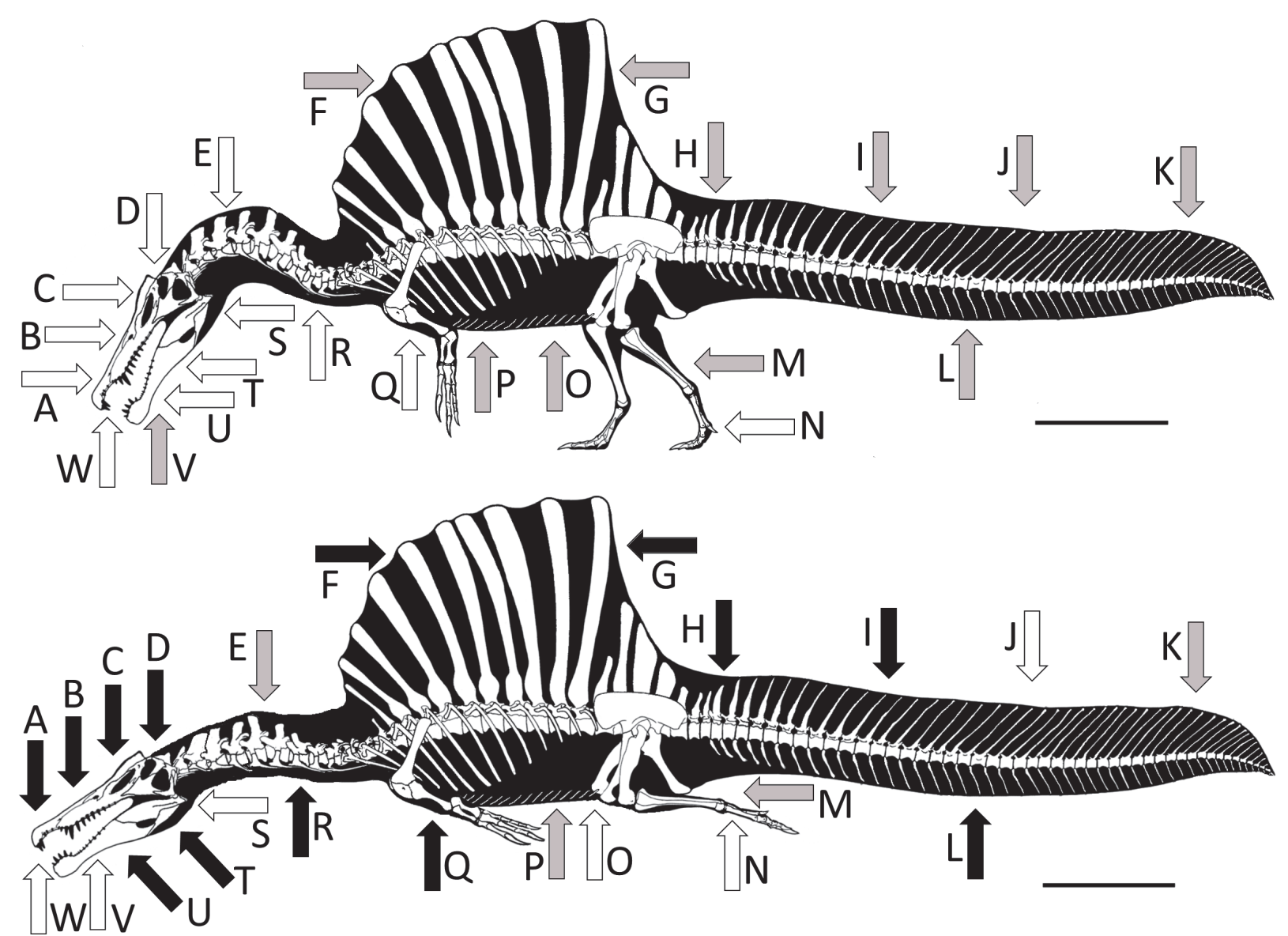

FIGURE 1. Skeleton in a standing posture as if dip fishing in water following the wading model, and in a swimming posture (based on Ibrahim et al., 2020a) following the pursuit predator model. A non-exhaustive set of lines of evidence as described in the text are indicated by arrows that either directly support either model (white arrow), are ambiguous or do not contradict the model (grey arrow), or actively contradict the model (black arrow). Key traits are as follows: A) laterally compressed skull, B) nares position, C) mechanical jaw performance, D) orbit position, E) neck stiffness and posture, F) non-hydrodynamic shape, G) instability in water, H) sub-anguilliform locomotion, I) thin caudal neural spines, J) tail propulsion, K) distal tail flexibility, L) low swimming efficiency, M) somewhat reduced hind limbs, N) enlarged 1st toe, O) pachyostosis, P) pneumatic elements, Q) forelimbs not reduced, R) neck ventriflexion, S) quadrate shape, T) head posture (as determined for Irritator), U) isotopic data from teeth, V) tooth enamel ridges, W) rostral sensory system. Skeleton modified from the original by Genya Masukawa (used with permission) and scaled to the size of the neotype. Scale bar is $1 \mathrm{~m}$.

inated the initial PC1 rendering this uninformative. We therefore took skull length and used this to scale the other sets of data to make them dimensionless. Skull length is a poor indicator of overall body size given the presence of longirostrine taxa in the analysis, but in the absence of good body size estimates for the wide variety of taxa covered here, we considered it appropriate. We then used these dimensionless data to construct a new PCA using the PAST 4.03 software package (Hammer et al., 2001). Missing cells (11 empty entries out of 210) were replaced using the iterative imputation protocol.
The unguals of Spinosaurus have been described as being flattened and appropriate for swimming (Ibrahim et al., 2020). Bony unguals, in the absence of keratin sheathes, give an approximate estimate of claw shape, which can still be informative for the habits of the animals that possess them (including dinosaurs and other reptiles, Birn-Jeffrey et al., 2012). Although simple geometric analyses of shape can be less effective than complex geometric morphometrics at distinguishing shape of unguals and behaviours (at least in birds, Tinius and Russell, 2017) it should be sufficient to assess if Spinosaurus has fundamentally 


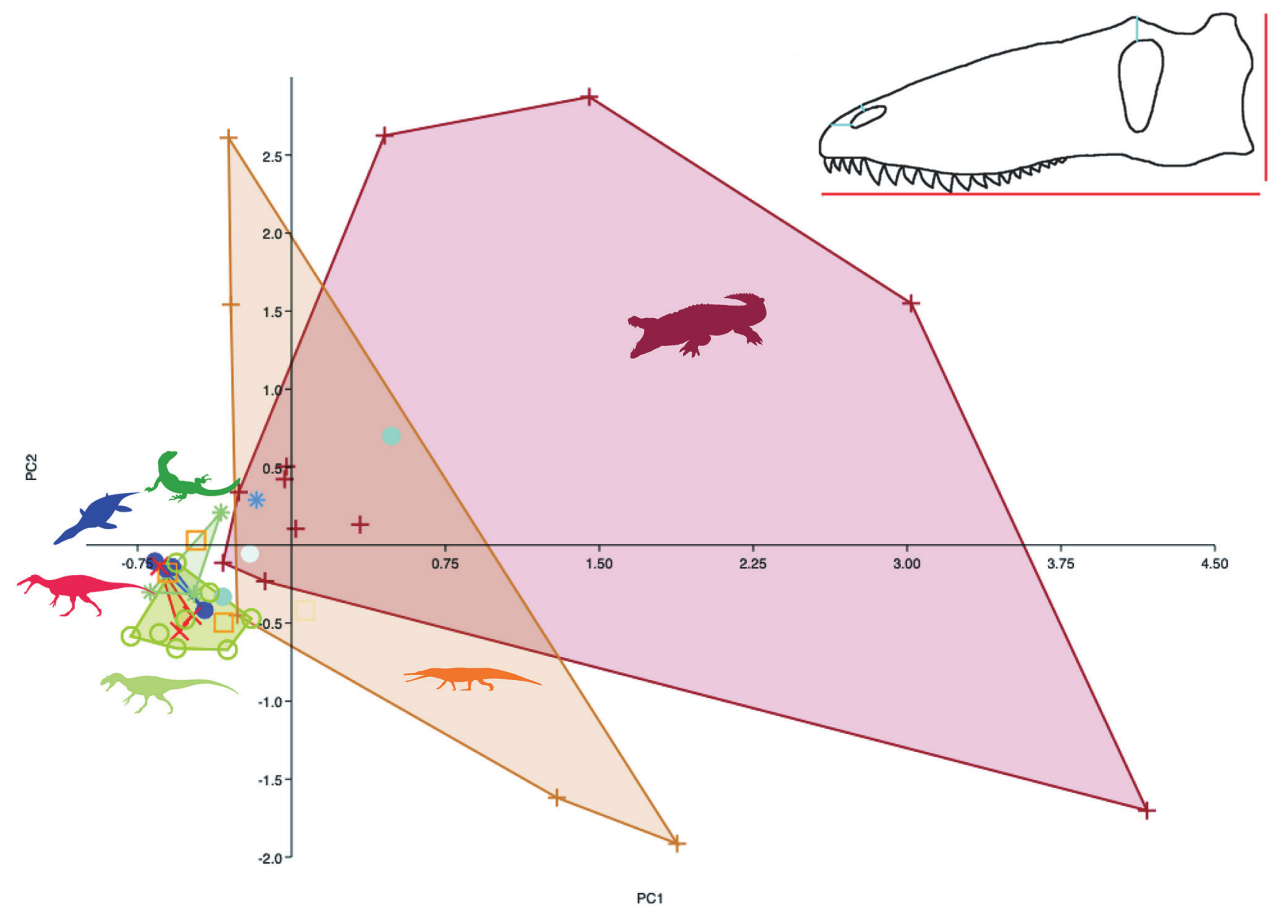

FIGURE 2. Principal Components Analysis of various measurements of the skull rescaled to skull length. Principal Component 1 (83.5\% of variance) plotted against Principal Component 2 (13.7\% of variance), plotted using eigenvalue scale. The red point is Spinosaurus, yellow are other spinosaurids, green are terrestrial taxa, pale blue are semi-aquatic, and dark blue, fully aquatic animals. Silhouettes are from PhyloPic.org and color-coordinated with the lines of the convex hulls for the groups of taxa they represent: the red Suchomimus (representing Spinosauridae; red Xs), the light green Allosaurus (representing non-spinosaurid Theropoda; open light green circles), and the orange Paleorhinus (representing phytosaurs: light brown pluses) are by Scott Hartman; blue Peloneustes (representing Plesiosauria: solid dark blue circles) by Nobu Tamura; dark green Varanus (representing terrestrial lepidosaurs: green asterisks) and dark brown Crocodylus (representing Crocodyliformes: dark brown pluses) by Steven Traver. Additional taxa plot include thallatosuchians (solid light blue circles), the mosasauroid Plotosaurus (blue asterisk), the nothosauroid Lariosaurus (solid aqua circle), and freshwater semi-aquatic lepidosaurs (open orange squares). The inset shows a reptile skull and how measurements were taken for the data used here and in Figure 3.

different shaped unguals to other large theropods. We collected data from the literature and photographs of theropod specimens (see Appendix 1). As far as possible we selected taxa that were relatively large bodied and were phylogenetically close to the megalosauroids. For each ungual the internal angle was measured by taking a line drawn between the ungual tip and the base in lateral view, this is then bisected by a perpendicular line until it contacts the ungual at point. Lines were drawn from this midpoint to the edges and the internal angle measured. This angle was then plotted against the length of the ungual.

\section{RESULTS}

\section{Skull Shape}

The results of the Principal Components Analysis of the skull measurements scaled to skull length are shown in Figure 2. The component loadings (Table 1) show that PC1 (which explains $83.5 \%$ of the variance) is influenced predominantly by naris to the dorsal margin of the skull. In PC2 (which explains $13.7 \%$ of the variance), the position of the orbit is the most important. No one feature dominates and all five sets of data influence the positions of the taxa.

As seen in Figure 2 the fields for crocodyliforms and for phytosaurs are far larger than the range seen in the other taxa. Spinosaurus and the other spinosaurids plots with the field of non-spinosaurid theropods, and overlaps in part with the field 
TABLE 1. Component loadings for the Principal Components Analysis of skull shape in Spinosaurus and other reptiles shown in Figure 2.

\begin{tabular}{lccccc}
\hline & PC1 & PC2 & PC3 & PC4 & PC5 \\
\hline Skull height & 0.010 & 0.005 & 0.035 & 0.979 & -0.202 \\
Skull width & 0.002 & -0.006 & 0.003 & 0.202 & 0.979 \\
Naris to anterior margin & 0.015 & 0.002 & 0.999 & -0.035 & 0.004 \\
Naris to dorsal margin & 0.970 & -0.242 & -0.014 & -0.009 & -0.001 \\
Orbit to dorsal margin & 0.242 & 0.970 & -0.006 & -0.006 & 0.007 \\
\hline
\end{tabular}

for non-mosasaur lepidosaurs. However, within this same region are the plesiosaur skulls. Thus, this analysis fails to clearly discriminate between terrestrial, aquatic and semi-aquatic taxa (Figure 2). It should be noted that in all three cases of Spinosauridae examined, the skulls of these animals are incomplete, and in particular the total length is uncertain. In the data here we have measured Baryonyx based on the reconstruction used in Hone and Holtz (2017), which is considerably longer than that of Charig and Milner's (1997) version, and the latter is closer to that of Spinosaurus.

We also present simple straight-line regression comparisons of the individual lines of original data scaling the skull length against the other data and also skull width vs height (Figure 3) to see if there are clear relationships between these data. For skull length vs height, length vs width, and skull width vs height Spinosaurus plots between the terrestrial and fully aquatic regressions, but not close to the semi-aquatic groups. There is considerable scatter in the various data, but there is no clear reason to infer from this that Spinosaurus has a skull shape that is similar to semi-aquatic animals.

For the distance of the naris to the anterior margin of the skull there is clear separation in the data with a few taxa having a posteriorly retracted naris. These include some semi-aquatic taxa such as phytosaurs and a pliosaur. Spinosaurus is however, relatively well separated from both the terrestrial and semi-aquatic tend lines. Although not as exaggerated, the other spinosaurs also plot away from these two ecotypes. However, Spinosaurus has a much greater distance for the naris to the dorsal margin of the skull for its size than almost any other taxon. Although there is one giant pliosaur with a similar pattern, the other taxa with low nares (and so a large length to the dorsal margin) are predominantly terrestrial taxa, including other spinosaurs. Finally, in terms of the orbit position, Spinosaurus is closer to terrestrial animals than fully aquatic and well separated from semi-aquatic taxa.

\section{Ungual Shape}

Measurements show that Spinosaurus (and other specimens referred to Spinosaurinae) do have flattened unguals and values around 165 degrees. However, it is not unique among largebodied theropods in this regard. Values recorded for Majungasaurus, Sinraptor and Gallimimus are similar or even higher than that of Spinosaurus and Compsognathus and an indeterminate abelisaur are only slightly below the values of $S$. aegyptiacus (see Appendix 1). Although there seems to be a weak tendency (slope $=0.044$ ) for larger theropods to have flatter unguals (Figure 4), this relationship is not statistically significant $(p=0.4)$ for our dataset.

\section{DISCUSSION}

\section{Skull}

Spinosaurus was described by Ibrahim et al., (2020a) as having "retracted nares, interlocking conical teeth and a rostromandibular integumentary sensory system" and by Arden et al. (2018) as also having dorsally positioned eyes. As noted by Hone and Holtz $(2017,2019)$ and following other authors (Charig and Milner, 1997; Sues et al., 2002) the nares of spinosaurids are retracted posteriorly but not dorsally (Figure 5). As such they are not positioned on the top of the head and close to the dorsal margin of the skull as in so many aquatic and semi-aquatic animals (Figure 3). Thus, as pointed out by Hone and Holtz (2019) a substantial portion of the head would need to be above the surface to keep the nares clear of the water (Figure 6 ). This lies in contrast to the resting posture of animals such as hippos (Hippopotamus) or crocodylians (see Hone and Holtz, 2019, figure 1), and presumably other taxa with dorsally-placed nares, such as the Triassic phytosaurs (e.g., Stocker and Butler, 2013).

Ibrahim et al. (2014) following Dal Sasso et al., (2005) suggest that the external nares in Spinosaurus might be as anteriorly positioned as the 


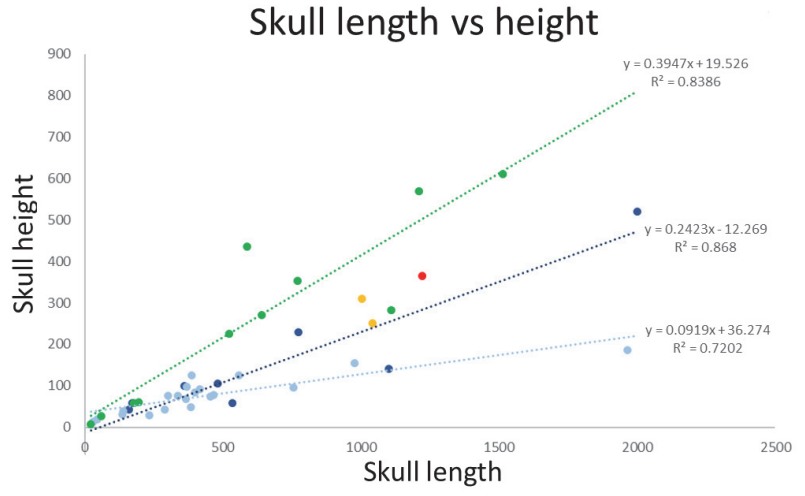

Skull length vs width
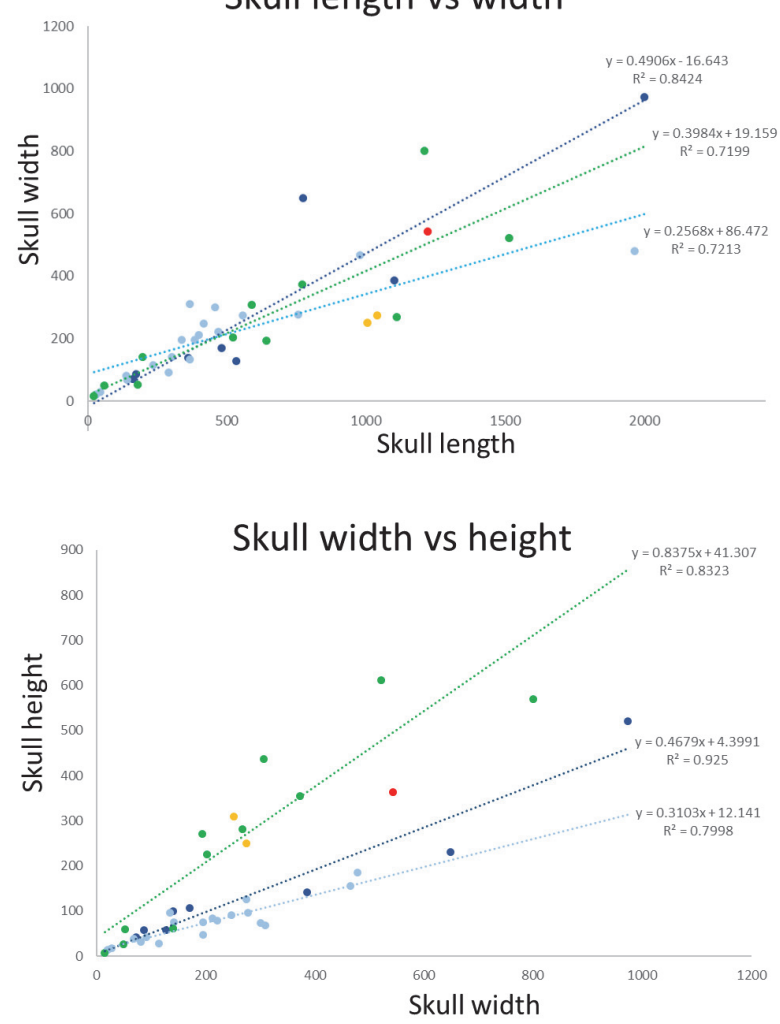

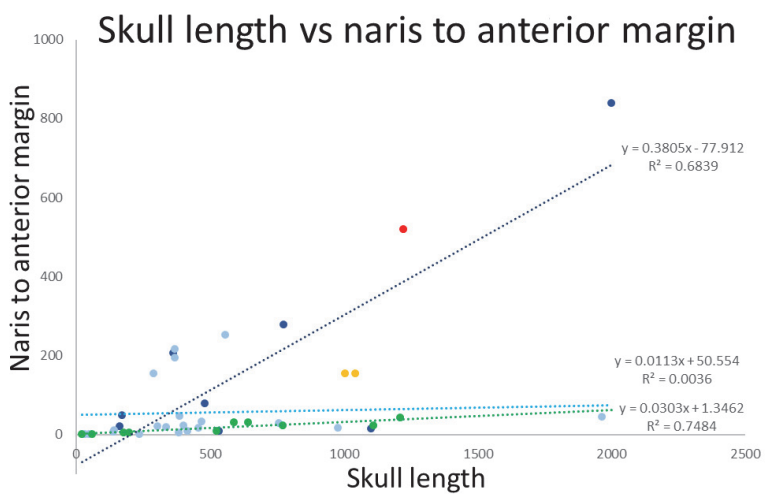

Skull length vs naris to dorsal margin
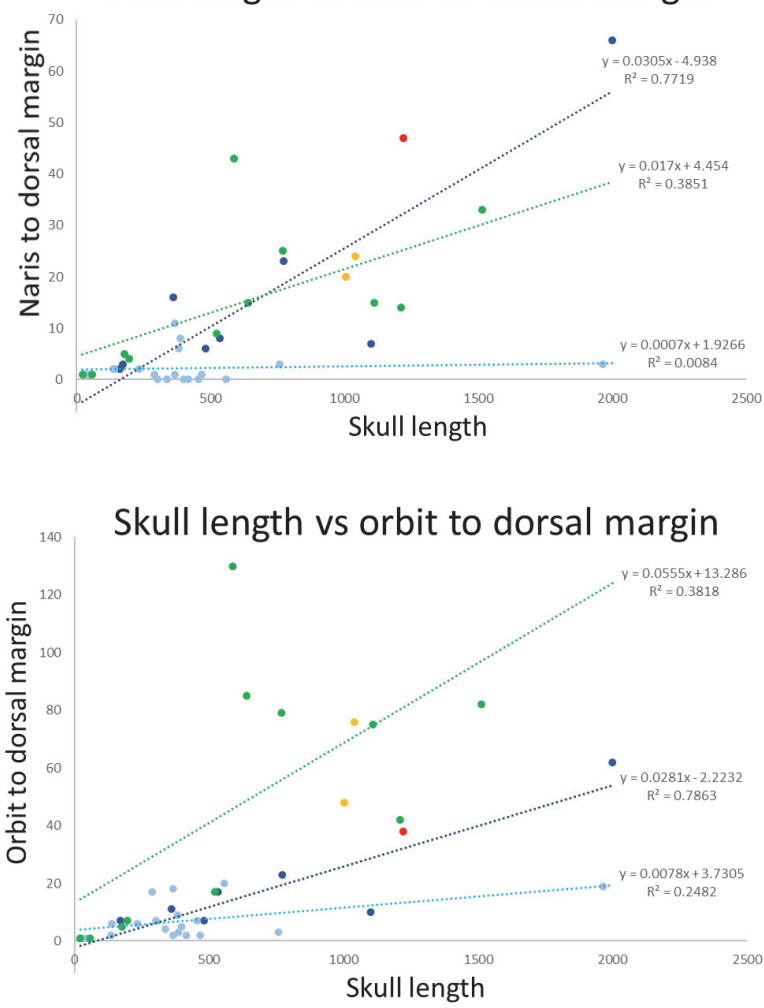

FIGURE 3. Graphs of various skull measurements to show the relationship between skull shape for different ecotypes. The red point is Spinosaurus, yellow are other spinosaurids, green are terrestrial taxa, pale blue are semi-aquatic and dark blue, fully aquatic animals. Least squares regressions are given for the terrestrial, semi-aquatic and aquatic datasets (the various spinosaurids were not included in these calculations), and the $\mathrm{R}^{2}$ values for these regressions are given.

subnarial foramen. If so, this would shift the position anteriorly, but in the specimen illustrated in Dal Sasso et al. (2005) this would still leave the external nares at least $47 \mathrm{~mm}$ from the dorsal margin of the skull and $185 \mathrm{~mm}$ from the anterior margin. Such a position would place the naris in a comparable position to that seen in Baryonyx which has a more anteriorly placed naris (Figure 5), and in contrast to semi-aquatic animals and even most aquatic animals (that do not typically rest at the surface) seen here.

Similarly, the eyes are not dorsally positioned in Spinosaurus compared to many aquatic and semi-aquatic animals (Figure 3, and also see Hone and Holtz, 2019). This would suggest that they did not habitually rest submerged in water in this manner and so were less specialised as semi-aquatic animals than taxa such as phytosaurs and croco- 


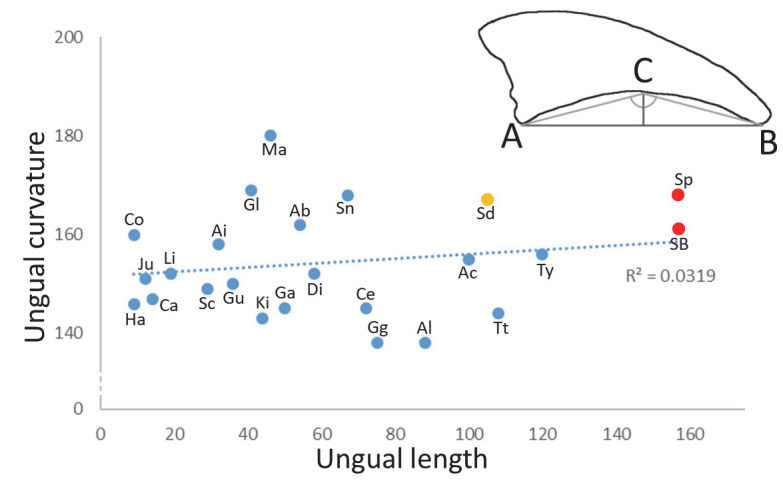

FIGURE 4. Graph of theropod ungual curvature vs ungual length. The inset shows how the curvature of the unguals was measured. In lateral view a line $A B$ is drawn between the ungual tip and the base. This is bisected by a perpendicular line until it contacts the ungual at point $C$. Lines are drawn from $A$ to $C$ and $A$ to $B$ and the internal angle measured. Unguals of Spinosaurus are in red, a further specimen attributed to a spinosaur is in yellow, and individual specimens are abbreviated as follows: Ab, abelisaurid; Ac, Acrocanthosaurus; Ai, Alioramus; Al, Allosaurus; Ca, Caudipteryx; Ce, ceratosaur; Co, Compsognathus; Di, Dilophosaurus; Ga, Gaulicho; Gg, Gigantoraptor; GI, Gallimimus; Gu, Guanlong; Ha, Halszkaraptor, Ju, Juravenator, Ki, Kileskus; Li, Limusaurus; Mj, Majungasaurus; Sc, Spectrovenator; Sd, spinosaurid; Sn, Sinraptor; Sp, Spinosaurus; SB, Spinosaurus B; Tt, Tyrannotitan; Ty, Tyrannosaurus.

dylians, and also the pattern seen in cetaceans (Heyning and Mead, 1990). This therefore suggests why the data for orbit position for semiaquatic taxa lies away from both terrestrial and aquatic taxa (Figure 3). Posteriorly, but not dorsally, retracted nares would however allow an animal standing next to, or in, water to hold the snout below the surface and to strike at or forage for aquatic prey while still being able to breathe (Hone and Holtz, 2019; Schade et al., 2020) (Figure 7).

The skull of Spinosaurus shows some basic convergences with other piscivorous taxa in the shape of its skull and in particular the notched jaws and premaxillary rosette (e.g., Rayfield et al., 2007; Vullo et al., 2016). However, it is also not that well adapted to be a dedicated piscivore compared to various piscivorous taxa that have very slender jaws with numerous interlocking teeth e.g., the gharial (Gavialis), dolphins (Tursiops, Platanista) and gar (Lepisosteus) (Whitaker and Basu, 1983) and piscivorous ichthyosaurs (Sander, 2000). In this regard, baryonychines are arguably more specialist piscivores with around twice as many teeth as spinosaurines (Sales and Schultz, 2017; Heckerberg and Rauhut, 2020) (Figure 5).

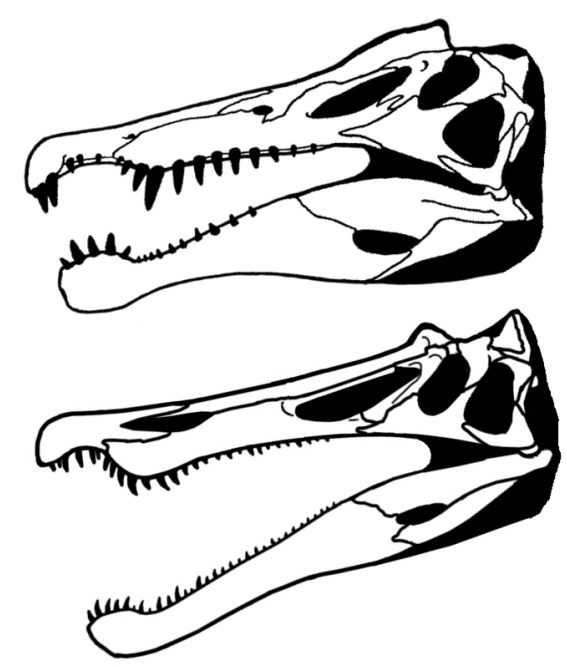

FIGURE 5. Comparison of skull shape of Spinosaurus and Baryonyx scaled to the same size. The two are very similar, which although this may be expected from their shared evolutionary history would suggest that they fundamentally forage in similar ways for similar prey, which contradicts the idea that one is an aquatic specialist. Not to scale.

The teeth of spinosaurids also show remarkable variation in terms of ornamentation, degrees of compression and presence or absence of serrations (Hone et al., 2010) though Spinosaurus itself does typically have teeth that lack serrations but do have fluting of the enamel. In the former trait they are similar to the teeth of aquatic and semi-aquatic predators such as mosasaurs, cetaceans and modern crocodylians and enamel ridges are seen in aquatic predators (McCurry et al., 2019). However, although this would support feeding on aquatic prey, it does not necessarily require that the predator itself to have been aquatic. Future analysis of tooth microwear on the enamel of spinosaurids could be revealing in this regard and provide an additional line of evidence to interpret their diet.

Based on the dietary categories of Massare (1987) the teeth of Spinosaurus most closely fall into the Grasp/Smash or their Grasp/Crunch Guilds of predators. These feed on harder prey such as fish with hard scales and crustaceans and perhaps ammonites or similar shelly taxa (Massare, 1987). This aligns with the study of Heckerberg and Rauhut (2020) showing that spinosaurines had unusually fast tooth replacement rates, and we suggest that these points are linked with the potential to feed on hard and slow items (crustaceans, chelonians, armoured fish), which would wear teeth rapidly and require frequent replacement. 


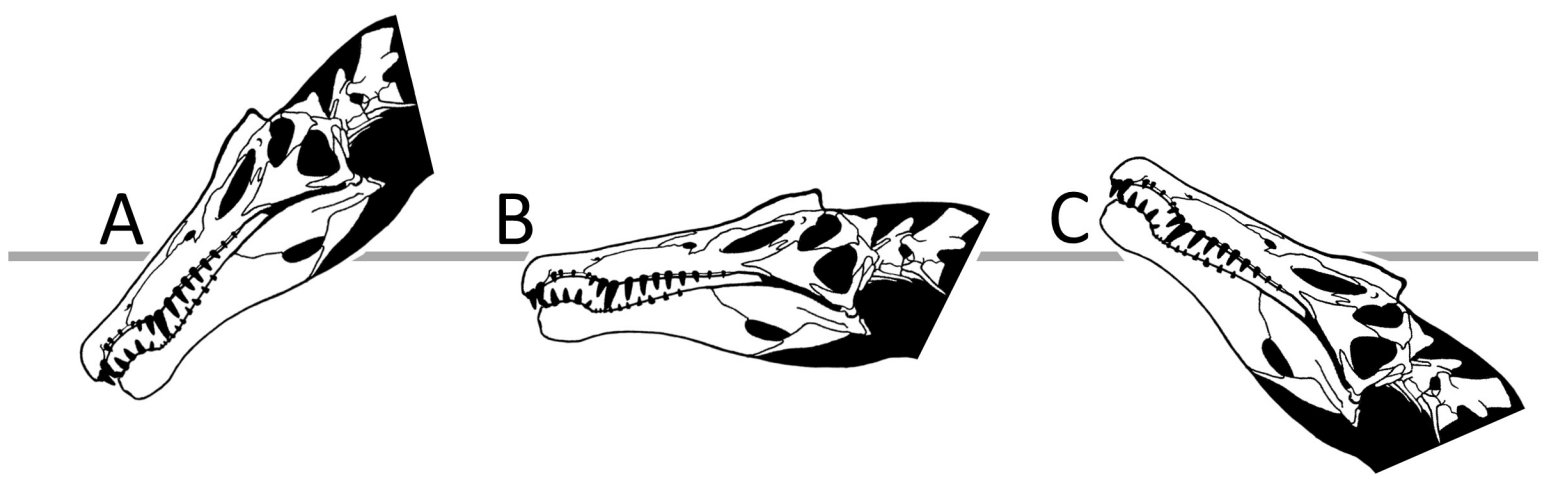

FIGURE 6. Suggested head positions of Spinosaurus relative to water. A) when dipping the snout in the water to forage while leaving the naris above the waterline as per the wading model. Head angle of 45 degrees based on Schade et al. (2020) for Irritator. B) while lying submerged, keep the naris and orbit clear of the water while minimising the amount of head that is exposed as per Arden et al. (2019), C) fully submerged as if coming up for air and trying to expose only the nares to breathe. Scale bar equals $1 \mathrm{~m}$.

The teeth of Baryonyx were closer to the General Guild (Massare, 1987) that feeds on smaller fish.

In addition to tooth morphology, the taphonomy of Spinosaurus teeth has been used as evidence for an aquatic lifestyle. Beevor et al. (2020) demonstrate that the teeth of this dinosaur are among the most commonly recovered remains in a pair of localities of differing lithologies in the fluvial portion of the Kem Kem Group of Morocco. Spinosaurid teeth are among the numerically dominant fossils at this site (rivaled only by remains of the sawfish Onchopristis and, at one site, ornithocherid pterosaur skeletal elements). In contrast, non-spinosaurid theropod teeth are only $1-5 \%$ as common. They infer from this that Spinosaurus was an inhabitant of the channels, living within the river itself. However, such difference in abundance might instead reflect the spinosaurid obtaining food within the river, but not necessarily spending most of its non-feeding time in this environment.

Additionally, the recent work of Heckeberg and Rauhut (2020) demonstrates that the rate of replacement of spinosaurid teeth exceeds that of other large theropods, including those of abelisaurids and allosauroids (the clades which contain the other large-bodied carnivores of early Late Cretaceous North Africa). They note the combination of higher replacement rate and greater tooth count over all may result in spinosaurids being overrepresented in surveys of dental material with respect to their actual fraction as individual animals in the paleoenvironment. It should be noted if spinosaurids were indeed specialists on obtaining and dispatching prey in the river itself (regardless of whether they were swimming or standing at the time), while their sympatric theropod relatives with slower tooth replacement rates were feeding mostly on land, the net result would be a far greater occurrence of spinosaurid teeth in the water than those of their terrestrial-feeding kin (see also Fanti et al. [2014] for evidence that shed spinosaurid teeth in Aptian-Albian Tunisia are associated with estuarine and coastal habitats, while shed teeth of other large theropods are more common in upland environments).

The rostrum of Baryonyx was initially shown to function more like that of a gharial with an elongate snout, than that of an alligator with a flattened rostrum (Rayfield et al., 2007 - though comparisons to a crocodile were not made), and it was suggested that therefore smaller fish may have been a substantial part of the diet (which would fit with Massare's General Guild noted above). Spinosaurus does have a snout broadly similar to that of Baryonyx (Figure 5) though the larger size and more robust teeth may suggest it was capable of taking larger prey. More recent analyses by Cuff and Rayfield (2013) showed that the rostra of Baryonyx and Spinosaurus mechanically performed similarly to one another, and they suggested that the two taxa functioned in similar ways. This would argue against Spinosaurus being a specialist that hunted as an aquatic predator in a different manner to the more terrestrial baronychines. Both taxa were again matched to a gharial in performance, though Cuff and Rayfield (2013) noted that the absolute size of the dinosaurs gave them greater mechanical performance than that of other crocodylians that are better adapted for resisting torsion. As such spinosaurines do not appear to be limited to small prey and could also engage and capture terrestrial prey (Cuff and Rayfield, 2013). Smaller 

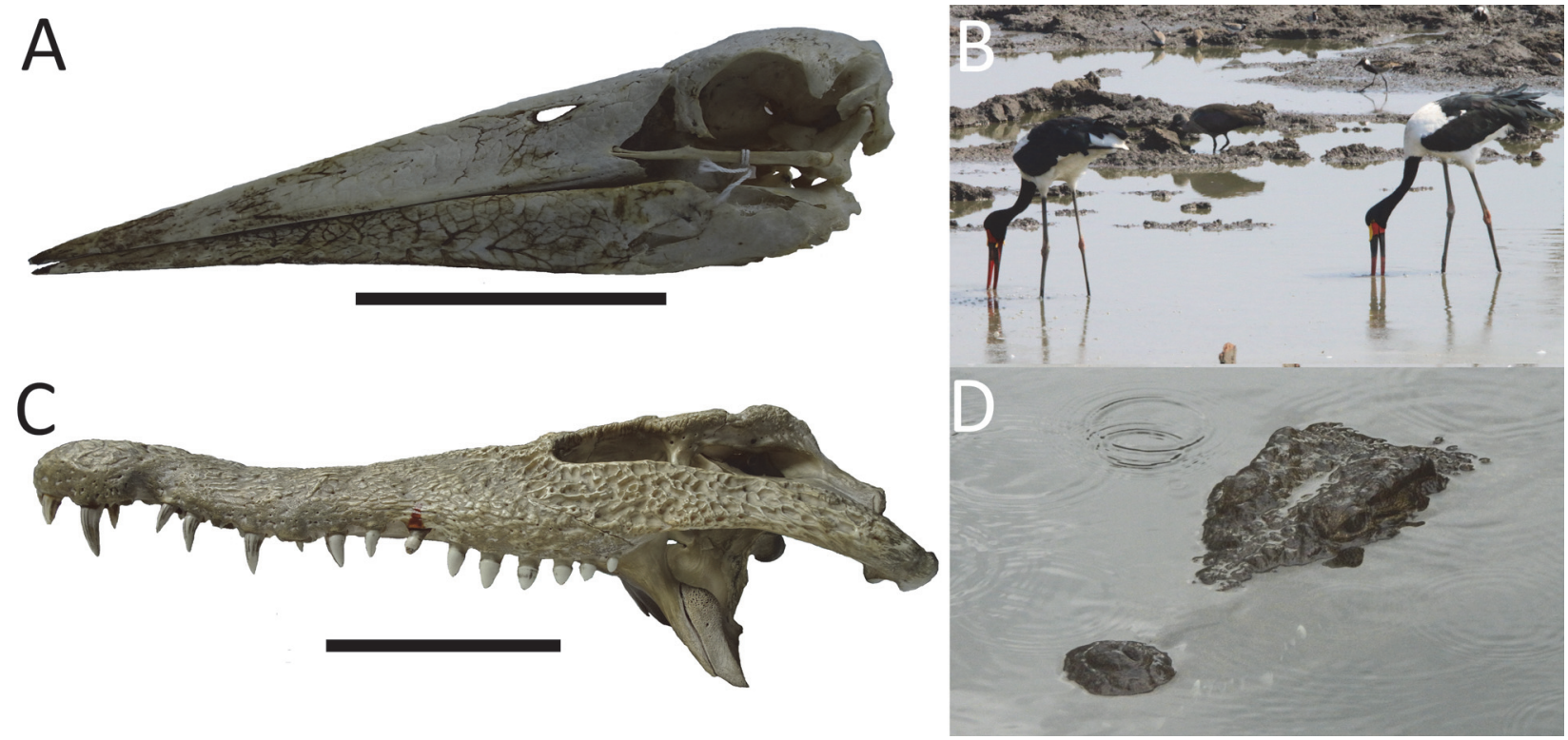

FIGURE 7. A) Skull of a stork (Leptoptilos - scale bar is $100 \mathrm{~mm}$ ) with a posteriorly retracted naris allowing them to forage while keeping the nares free of the water as in B) showing Ephipporhynchus senegalensis feeding. Although proportionally much further back here than in Spinosaurus, the absolute distance of the naris from the anterior tip of the jaw is less in the stork. C) Skull of crocodylian (Crocodylus - scale bar is $100 \mathrm{~mm}$ ) with dorsally positioned naris allowing them to rest with minimal exposure of the head as in D) Crocodylus niloticus resting at the surface (image courtesy of Jonathan J. Meisenbach).

individuals would not enjoy such advantages, and we suggest that they may have been more limited in their diets as they would then have snouts that performed poorly in bending and would have functioned more like gharials (Cuff and Rayfield, 2013). Here, smaller spinosaurids may have adopted a gharial-like mode of feeding by slashing the head laterally through the water (Cuff and Rayfield, 2013), which we suggest could be adopted with just the snout, or with the whole animal in the water. However, the lateral flattening of the skull of spinosaurids is relatively common in theropods but lies in sharp contrast to the normally dorsoventrally flattened heads of many semi-aquatic animals such as crocodylians (Figure 3 ). This would suggest that rather than lateral strike (McHenry et al., 2006; Pierce et al., 2008, 2009), a vertical strike for spinosaurids would be most efficient at moving through the water (see also the section on neck ventriflexion below), and indicates they were not normally striking while submerged.

Examination of isolated quadrates referred to spinosaurines from the Kem Kem Group (Hendrickx et al., 2017) suggest that these animals were suited to rapid, but not strong, bites. They also suggest that the jaws were adapted to swallow larger items (Hendrickx et al., 2017), and while such adaptations are seen in piscivores (which are not easily able to manipulate food and lack the cutting teeth of most theropods to break up prey), it does not limit them to fish (cf. large modern crocodilians - Hanson et al., 2015). Such adaptations would favour catching and processing aquatic prey, but would potentially be beneficial to animals under both the wading or pursuit models.

As already noted by Hone and Holtz (2019), the putative sensory system described for spinosaurids (Ibrahim et al., 2014a) is not unique to these animals, but present in other large theropods, which lack any obvious connection to aquatic foraging (Neovenator - Barker et al., 2017; Daspletosaurus - Carr et al., 2017). Porter and Witmer (2020) note that based on the available data of archosaurs, there is no a priori reason to think any theropods had increased rostral sensitivity over others (although they did not look at spinosaurids specifically). As such, there is no particular reason to think that the snout foramina in Spinosaurus correlates with aquatic foraging. Even if it did, such a system would benefit animals foraging in the manner of the wading model or that of a pursuit predator and would not support one model over the other. Detecting approaching food items with a snout dipped in the water would serve just as well as detecting them while entirely submerged. 
Based on the neuroanatomy of the skull, Schade et al. (2020) posited that the large spinosaurine Irritator had a habitual head-down posture, and that the internal ear structure suggests an animal for which vertical head movement was important. This would support the wading model (indeed, it would be predicted as the standard wait-and-see posture while foraging), but would not fit with an aquatic pursuit model where a habitual head-down posture would be inappropriate for a swimming animal or one residing on the surface. In particular, this posture would be at odds with the purported dorsally-positioned orbits and nostrils, as this would direct these further into the water assuming the animal was residing or swimming at the surface (cf. Figure 6). Clearly, Spinosaurus may differ in this regard from Irritator, but it does show that at least one spinosaurine was similar in this regard and in general the skulls of these animals (where known) are overall very similar suggesting similar habits and selection pressures.

Collectively, therefore, the data from the skull either supports the wading model and is poor support for an aquatic pursuit specialist (nares, orbits, dentition, overall mechanical performance) or is equivalent and could be considered support for either model (sensory apparatus, mechanical performance of juveniles, quadrate morphology).

\section{Neck}

The cervical vertebrae of Spinosaurus are described by Ibrahim et al. (2014) as being long, and they are illustrated by Ibrahim et al. (2020a, their supplementary figure 3 ) with elongate cervical ribs that extend and overlap fully at least one posterior cervical to their origin. This would be similar to the condition in Suchomimus where the cervical ribs extend over two following cervical vertebrae as well (S. Evers, personal commun., Nov., 2020). As noted by Taylor and Wedel (2013), elongate cervical ribs may have played an important role in ventrally stabilizing the neck, and counteracting gravity, with stiff (and overlapping) cervical ribs providing lateral stabilization for the neck and provided resistance against torsion of the neck.

Pursuit predation in water may lead to increased stiffness in the cervical series (e.g., Molnar et al., 2015 - Metriorhynchus) suggesting possible support for this model. On the other hand, such animals have short and robust necks, and not long and relatively gracile ones. Aquatic piscivorous predators with necks considerably shorter than their skull length (typically only half as long or shorter) include thalattosuchians (Johnson et al.,
2020), cetaceans and phytosaurs (Stocker et al., 2017). In contrast, reconstructions of the anatomy of Spinosaurus (e.g., Ibrahim et al., 2014) show a skull only as long or shorter than the cervical series.

An animal living predominantly in water would already have support for a long neck, and the work of Rayfield et al. (2007) and Cuff and Rayfield (2013) suggest rapid lateral movements through the water would be necessary to catch fish underwater and would potentially require the neck to move both freely and rapidly in multiple directions to catch agile prey.

It is worth noting that the total neck length and cervical vertebrae count in aquatic and semiaquatic amniotes is frequently reduced (Bucholtz, 2001a, b; Demarco et al., 2018). Although the full cervical count is unknown in Spinosaurus, basal tetanurans typically have 10 cervical vertebrae, and the contemporaneous Sigilmassasaurus (which Ibrahim et al., 2020b consider to be $S$. aegyptiacus) retains articular facets that would indicate a sigmoidal posture of the neck (Evers et al., 2015) unlike the near straight one illustrated by Ibrahim et al. (2020a, their figure 1).

Evers et al. (2015) noted that Sigilmassasaurus and the original Spinosaurus material of Stromer have strong rugosites on the ventral surface of the cervical vertebrae that correlate with strong musculature, and would be an adaptation for ventriflexion of the neck. Such an action would have a clear benefit to an animal fishing with only the snout in water, either to hold the head or to thrust down at prey (this would also potentially be useful on land for targeting small prey items) and would align with a dorsoventrally S-shaped neck posture. This would support the wading model, but there is no reason to think strong ventriflexion would benefit a pursuit predator foraging in the water column where prey could potentially travel in any direction.

In short, the neck would appear to support a wading model in terms of vertical lunging, and the stiffness argument could be used to support or oppose either model depending on the context of how it may have functioned.

Tail

Spinosaurus is now shown to have had caudal vertebrae with tall neural spines and long chevrons, and these are interpreted to have supported "a large, flexible fin-like organ capable of extensive lateral excursion" (Ibrahim et al., 2020a, p1). The tail shows reduced pre- and postzygapophyses, 
which would increase flexibility, and this is particularly apparent in the distal tail compared to other theropods where this area is generally stiffened (Ibrahim et al., 2020a). Collectively these adaptations were hypothesised to function for aquatic propulsion.

Some anatomical adaptations to swimming might be expected in the tail of Spinosaurus if it was a strong swimmer. For example, Persons et al. (2015) note that the expanded ventral tips of the chevrons of an oviraptorosaur would provide enlarged surfaces for the insertion of the $m$. ischiocaudalis, which they describe as a muscle critical in controlling lateral and ventral tail flexure. This might be expected in the tail of a sculling theropod, but there is no such enlargement here. SchwarzWings et al. (2009) demonstrated that the caudal vertebrae of both extant crocodilians, and those of the more aquatic dyrosaurids, have extensive rugose attachments for a complex of muscle groups along their neural spines and transverse processes. Dyrosaurids have elongate neural spines broadly similar in lateral profile to those of Spinosaurus, (although the rugose patches on the transverse processes were limited to the anterior portion of the tail). Similarly, Lindgren et al. (2009) showed that some of the more aquatically-adapted varanids ('water monitors') have a rugose texture and deep striations to the distal parts of the neural spines that helps a plate of connective tissue, which forms something of a paddle (Young et al., 2008), attach to the vertebrae. In contrast, the described caudals in Spinosaurus have particularly slender neural spines that lack strongly rugose regions, suggesting far less development of propulsive muscles within its tail compared to e.g., crocodylians. This matches the reconstruction of (Ibrahim et al., 2020, figure 1d, e) that shows relatively little musculature.

To test the potential mechanical effect of the tail fin, Ibrahim et al. (2020a) created a simple robot to analyse the thrust and efficiency of the tail of Spinosaurus, which was found to be better than theropod dinosaurs, but rather lower than that of their crocodile and newt models. The methods of tail undulation for the robot "resulted in the tail tip undergoing peak-to-peak lateral excursions of approximately $40 \%$ of the proximodistal length, comparable to that exhibited by swimming axolotls and alligators" (Ibrahim et al., 2020a, p. 5), although their model lacked an increase in distal tail flexibility, which could affect these results.

An increase in tail flexibility has been seen for some swimmers that rely on undulation of the body and tail compared to less adept swimming relatives (e.g., Ringma and Salisbury, 2014). Increased flexibility is also seen in some large species that use whole body flexion to produce thrust (e.g., mosasaurs) but these are animals typically showing greatly reduced appendages to allow whole-body sine waves to be produced (Lindgren et al., 2011) which is not seen in Spinosaurus (see the Hind limbs section). More derived mosasaurs that are more specialist swimmers and do not move the whole body show stiffening of the distal tail to increase power output (Lindgren et al., 2011) suggesting that distal tail flexion would not have benefitted this form of swimming style. Alternately, tail stiffness can also be important to provide sufficient resistance and push against water while delivering thrust (Hildebrand, 1997). That said, a fluke on the distal part of the tail would have a poor lever arm for producing thrust (Thewissen and Fish, 1997), and it has been noted that the distal tail may contribute little thrust compared to the proximal part and can add to the drag in alligators (Fish, 1984).

Rapid aquatic pursuit predators that utilise tail propulsion typically show tails with strong segmentation into separate flexible displacement and stiffened distal propulsive units (Buchholtz 1998, 2001b; Lindgren et al., 2009), unlike the condition seen in Spinosaurus. In short, the increased flexibility of the distal tail of Spinosaurus is not obviously an adaptation for swimming and a formal hypothesis or model of how this increased flexibility would improve swimming is required.

Based on their analysis, Ibrahim et al. (2020a, p1) described the thrust and efficiency of the tail of Spinosaurus in water as having "performance...comparable to those of extant aquatic vertebrates that use vertically expanded tails to generate forward propulsion while swimming." However, crocodiles had an efficiency 1.5 times greater than that of Spinosaurus in their results. Although crocodylians are excellent swimmers compared to terrestrial animals, and are also better than some other semi-aquatic mammals, they perform poorly compared to other swimmers, most notably fish (Seebacher et al., 2003). The method of swimming of crocodylians has been described as being "characteristic of organisms adapted for low swimming speed and low efficiency, and low acceleration performance" (Fish, 1984). Seebacher et al. (2003) considered crocodylians not to be optimised for swimming, and Frey (1992) said that crocodiles prefer slower swimming and are not fast, long-range swimmers. Crocodiles also show a sustained swimming speed half of that of sea lions 
(Eumetopias) in terms of body lengths per second (Elsworth et al., 2003), and at least some large phocids actively pursue prey (Volpov et al. 2015). This contrasts with larger crocodylians that snap at fish that have come into range (Davenport and Sayer, 1989) rather than chasing them.

Therefore, the analysis of Ibrahim et al. (2020a) showing the performance of Spinosaurus to be well below that of a group that are themselves inefficient swimmers and not pursuit predators, stands in contrast to the suggestion that it is an aquatic specialised for pursuit predation. The adaptations highlighted by Ibrahim et al. (2020a) may well indicate that Spinosaurus had superior swimming abilities compared to typical theropods (including their close baryonychine kin), but that does not indicate they were adept swimmers in comparison to semi-aquatic or fully aquatic animals (as would be required for an animal which was a pursuit predator in the water).

\section{Hind limbs}

The hind limbs of Spinosaurus are unusual for theropods in that the femur is remarkably short for an animal of its size (Ibrahim et al., 2014a). Ibrahim et al. (2014a) had suggested foot-propelled swimming (and also suggested the tail may have been used), but this idea is not commented on in the 2020 paper, and only tail-based propulsion is discussed. Furthermore, it was described as having a long pedal digit I, the unguals are described as being relatively flat, and the possibility of webbing between the toes was proposed (Ibrahim et al., 2014a). A full description and anatomical comparisons of the phalanges and unguals to other clades is needed, but it is not immediately apparent why such an arrangement would support aquatic pursuit predation.

Bony ungual curvature may not correlate well with the ecology of animals (e.g., Birn-Jeffrey et al., 2012) and so may have limited power to predict the habits of extinct dinosaurs. As noted above (see Results), Spinosaurus does have unguals that are flattened compared to most other theropods. However, these are not uniquely flattened with other theropod taxa having a similar or even greater lack of curvature (Sinraptor, Majungasaurus, and an unnamed abelisaur), including large and carnivorous taxa and the degree of flattening may simply be a result of the large size of the animal (Figure 4). We hypothesise that larger, graviportal theropods, even macrophagous carnivores, may be less agile and/or less likely to use their feet during pre- dation attempts and so strong curvature may be less important for them.

Although considered an animal that swam using the forelimbs rather than the feet, the semiaquatic Halszkaraptor (Cau, 2020) does not have flattened unguals. As such the pedal unguals of Spinosaurus do not appear to be especially unusual in curvature at least and do not obviously correlate with body size or predatory behaviour or aquatic affinities.

This pattern is mirrored in modern birds. Manegold (2006) observed that grebes (Podicipedidae), which are foot-propelled swimmers, do have flattened unguals, though so too do flamingoes (Phoenicopteridae) which are waders but not adept swimmers. Manegold (2006) only found flattened unguals elsewhere among seabirds in some storm-petrels (Oceanitinae, Hydrobatidae) and an extinct proceralliform, none of which are adept swimmers or divers. Flattened unguals were not present in foot-propelled divers including Anhinga (snake-birds), Gavia (loon), nor Tachybaptus (little grebe), or adept swimmers such as Laurus (gull), Fratercula (puffin) and Pelecanus (pelican), and he noted that other water birds typically had laterallyflattened and sharp claws (Manegold, 2006). In short, in swimming birds at least, there is no clear or strong correlation between flattened unguals and aquatic locomotion.

Some tetrapods may use both the limbs and tail together, or alternate depending on the situation (e.g., crocodylians - Fish, 1984; inferred for mesosaurids - Villamil et al., 2016; the giant salamander Andrias japonicas - DWEH pers. obs.). Presumably other reptiles with a similar combination of expanded (even webbed) feet and laterally compressed tails (e.g., choristoderes - Gao et al., 2000) might have swum in this fashion, but despite the wide array of extant secondarily aquatic and semi-aquatic reptiles, we are not aware of any that rely on a combination of both for pursuit predation. In any case, paddles are drag-based propulsors that operate well for surface swimming, but have low efficiency and produce large thrust only at slow speeds (Fish, 2016), so if the feet were webbed for swimming these would not support pursuit predation.

Species such as crocodiles and alligators do use their feet as part of their strike at prey, but are not active pursuit predators of fish (and nor are newts). Instead, they use a short-range lunge to strike at prey and the feet are used as part of this burst (see Fish, 1984 and references therein). If the feet of Spinosaurus are splayed with webbing, 
this would support this, and Ibrahim et al., (2014a) point to the legs being capable of powerful backward motion based on an enlarged caudofemoralis attachment. Thus, the arrangement of the feet could be used to strike at prey in water, but this action would be more consistent with burst ambush predation rather than agile pursuit predation.

We note that the arrangement of the toes and unguals may be necessary simply to support the weight of the animal on land. If the legs are reduced in size overall, a larger spread of toes and the use of the fifth toe could simply be required to help during normal terrestrial locomotion-the area of the foot on the ground would remain in proportion to the body of the animal even as the legs are reduced. Moreover, this spreading of the pedal digits (and even putative webbing) would also suit animals that foraged at the margins of water in and in moving across muddy or swampy ground. All other factors being equal, spreading the weight of an animal over a larger area would reduce their tendency to sink on soft ground. This is consistent with the wading model. Indeed, Ibrahim et al. (2014a) noted that the feet show similarities with shorebirds. As such, this data is consistent with the wading model. Reduced capacity for locomotion on land would perhaps argue somewhat against this, but would not rule it out, and if terrestrial locomotion was primarily limited to moving between patchy resources and not normally required to pursue terrestrial prey on land this is less of an issue.

The hind limbs of Spinosaurus do potentially provide evidence for aquatic locomotion and even striking at prey underwater, but specifically not in the sense of pursuit predation. Indeed, as Henderson (2018) notes, aquatic adapted animals would be expected to have even smaller hind limbs than Spinosaurus does, to further reduce drag. Massare (1988) similarly points to greatly reduced limbs being a common feature of even relatively poor swimmers, which are not seen here. On the other hand, phytosaurs are interpreted as being semiaquatic animals, but some do not have especially reduced limbs despite their aquatic affinities (Chatterjee, 1978) so there is not necessarily a clear pattern between limb reduction and swimming. Ibrahim et al. (2020) illustrate their Spinosaurus in a swimming posture with the femur held near vertically, very different to the posteriorly directed position used by swimming crocodiles and would potentially increase drag further in the theropod.

Indeed, the forelimbs of Spinosaurus, while known from very few elements (Ibrahim et al., 2020a), do not appear to be reduced relative to the animal as a whole and suggests there is no forelimb reduction in addition to the limited hind limb reduction. Henderson (2018) also pointed out that if terrestrial locomotion is limited and aquatic speed is important, Spinosaurus might therefore be expected to have reduced the caudofemoralis musculature and fourth trochanter. However, Ibrahim et al. (2014) describe it as having a robust fourth trochanter, and Smyth et al. (2020) diagnose the species as having "femur strongly bowed anteriorly with fourth trochanter hypertrophied, extending along $\sim 25 \%$ of the femoral shaft."

We note that Spinosaurus has a typically theropodan arrangement of lateral processes on the tail, suggesting a relatively normal arrangement of hindlimb muscles even with a shortened femur. This further argues against the idea of limited terrestriality and high levels of adaptation for aquatic locomotion in Spinosaurus.

Although modern herons and storks do have proportionally long legs, reduced limbs in Spinosaurus is not immediately a contradiction for the wading model. Since even a mid-sized Spinosaurus would have legs that were considerably longer in absolute terms than even the largest modern waders, it would be possible for it to stand in relatively deep water with the body, and especially head, free of the surface. The totality of the evidence from the hind limbs therefore does not support active pursuit predation but is at least consistent with the wading model.

\section{Aquatic Locomotion}

An important consideration of the ecology of Spinosaurus is its potential to swim. This includes its ability to accelerate, maintain a given speed, swimming efficiency, capacity to dive and adaptations for aquatic locomotion.

There are a number of different methods of locomotion in water used by reptiles. Spinosaurus is closest to the Bauplan II of Massare (1994), which also includes early ichthyosaurs, mosasaurs, nothosaurs and marine crocodiles (Massare, 1994) as well as mesosaurs and lizards (Villamil et al., 1996) having a relatively elongate and narrow body with a long and muscular tail which may be broad (Massare, 1994, although as noted above the tail of Spinosaurus is not well muscled compared to crocodiles). This body type is suited for acceleration over a short distance and ambush attacks, not pursuit (Massare, 1994). Similarly, Spiekman et al., (2020) noted that poor hydrodynamic shape of the long-bodied (and necked) Tanystropheus would make it a poor pursuit preda- 
tor. Features of aquatic predators that attack by lunging are those with elongated, cylindrical bodies and have a low-aspect ratio tail (Massare, 1988, 1994; Lindgren et al., 2011) which describe Spinosaurus. While crocodylians have been described as having greater efficiency than semi-aquatic mammals that use drag-based paddling, they are far below fully aquatic mammals in this regard, and slower than either in terms of top speed (Seebacher et al., 2003).

Traits associated with faster swimming species, including those described as pursuit predators, are not seen here. A spindle-shaped (fusiform) and very stiff body where only the tail moves (and is associated with a large and often semi-lunate fin) is seen in derived ichthyosaurus (Massare, 1994), some mosasaurs and metriorhynchids (Lindgren et al., 2010).

Trunk stiffness may also play a role in swimming. Fish (1984) described modern crocodilians as undulating from the pelvis and caudal series, though Sailsbury and Frey (2001) stated that crocodilians have developed lateral flexibility of the torso that functions in whole body sinusoidal movement in aquatic locomotion, and Weihs and Webb (1983) considered a flexible body allowing largeamplitude undualtions to be important for the optimising swimming transient (i.e., semi-aquatic) swimmers. The two are not necessarily mutually exclusive. Although a relatively rigid trunk can help increase speed of a swimming animal (LinghamSoliar, 1991), a flexible body is useful in making sharp turns. In other words, crocodylians may normally swim with a stiff trunk, but flexibility would be important, especially when catching prey. Sailsbury and Frey (2001) note that the flexibility of crocodylians is a derived condition from a stiff-trunked ancestor, suggesting that this increased flexion has been selected in association with swimming.

Spinosaurus would have had limited lateral flexion of torso given the large laterally directed transverse processes in the dorsal vertebrae (cf. mesosaurs - Villamil et al., 1996) and the dorsal sail, though it is not overly restricted with for example hyposphene-hypantra articulations or fused vertebrae, which would stiffen the trunk further. Spinosaurines do not appear to have made the trunk more flexible compared to their ancestors, and their dorsal vertebrae are fundamentally similar in structure to those of other megalosauroids, suggesting a lesser degree of adaptation to aquatic locomotion and less agility than compared to other type II swimmers though it may have facilitated greater speed. Certainly the sail was not highly flexible and would not function in the manner of sailfish (as suggested by Gimsa et al., 2016) where the sail is both flexible, collapsable and mediolaterally thin.

Critical to high speed swimming and pursuit predation is the reduction of drag (Massare, 1994; Hildebrand, 1996). This comes from numerous features such as reducing the frontal area of an animal (Massare, 1994) and reduced or retractable appendages (Hildebrand, 1996), and drag is more important for swimming animals of larger sizes, thus increasing size in aquatic birds and mammals is associated with drag reduction (Webb and de Buffrenil, 1990). Elsworth et al. (2003) noted that while absolute swimming speed increased from larger crocodiles, performance (measured as body lengths travelled per unit time) dropped, likely as a result of increasing drag.

An adult Spinosaurus, however, would encounter considerable drag. As noted above, the forelimbs do not appear to be reduced, and the hind limbs show limited reduction and are not shown as being capable of being folded against the body. The body shape is not spindle-shaped and the dorsal sail in particular would offer enormous pressure drag even if fully submerged. This drag would greatly limit both the acceleration and top speed of Spinosaurus when swimming. The sail would also likely induce turbulence from its trailing edge generating additional drag, and cannot be retracted. Furthermore, the ' $M$ ' shaped arrangement of the sail with a distinctive notch in the middle (as favoured by Ibrahim et al., 2014a, 2020a) would generate further drag with two tips than would a more typical D-shaped arrangement.

The dorsoventrally deep body coupled with the pneumatic nature of the animal would make it vulnerable to tipping over because of the differing centres of mass and buoyancy (Henderson, 2018). The exact extent of the pneumaticity of Spinosaurus is not known, but the cervicals and dorsals do at least show pneumatopores (as described by Ibrahim et al., 2020b) so this would not be negligible. This pneumaticity would be problematic whether the animal was partially submerged (swimming at the surface) or fully underwater, suggesting that any swimming would have had to be done in shallow waters. Although Henderson's paper predates the publication of the new tail material, we consider it unlikely that the presence of longer caudal neural spines and a putative fin on the tail would greatly affect the centre of mass of the animal relative to the centre of buoyancy and correct for this problem. 
Ibrahim et al (2014a; 2020a) have pointed to the pachyostotic nature of some Spinosaurus elements (which are commonly found in semi-aquatic animals - Houssaye, 2009) to support their interpretations. The exact density of Spinosaurus is unknown, but the rigorously reconstructed model of Henderson (2018) gave a figure of $833 \mathrm{~kg} / \mathrm{m}^{3}$, slightly higher than another large theropod in Allosaurus at $818 \mathrm{~kg} / \mathrm{m}^{3}$ but lower than Tyrannosaurus at $851 \mathrm{~kg} / \mathrm{m}^{3}$ and considerably lower than a model of Alligator at $952 \mathrm{~kg} / \mathrm{m}^{3}$. This strongly suggests Spinosaurus would be very positively buoyant. As Henderson (2018) points out, penguins (powerful swimmers that are very hydrodynamic) are pachyostotic but like Mesozoic theropods, are also pneumatic, and have to drive hard to swim down against their net buoyancy. Diving would therefore be an energetically costly activity for a positively buoyant Spinosaurus.

Surface swimming is considerably less efficient than submerged swimming (Fish and Baudinette, 1999) and incurs considerable extra wave drag for animals moving at, or just below, the surface (Hildebrand, 1996), potentially many times greater than the drag of a submerged body (Fish, 2000). Metabolic effort for swimming at the surface can be $70-100 \%$ higher than when free of wave drag (Alexander, 2003). Wave drag would be impossible to avoid with the sail unless it was well clear of the surface. This depth is at or deeper than 2.5 times the body diameter (Alexander, 2003), and the ability of Spinosaurus to submerge fully and maintain a submerged position would be critical given these enormous extra costs at the surface. This is an important point given that the tests of the mechanical tails by lbrahim et al. (2020a) were fully submerged and as noted above, even here Spinosaurus was already far less efficient than crocodiles. Furthermore, the size of the sail would mean that both deep water and the ability to reach and maintain a position deep in the water column would be required in order to avoid surface drag from the sail, which would greatly increase the costs of swimming (down) and limit areas in which it could forage effectively.

The body of Spinosaurus is not a cylinder but closer to that of an oval, but even taking the body diameter to be the mediolateral width would give a value of $85 \mathrm{~cm}$ (measured from figure 7 of Henderson, 2018). Multiplied by 2.5 for the depth to avoid surface drag gives a figure of at least $2.1 \mathrm{~m}$, requiring the dorsalmost part of the animal be at least this far below the surface. However, given that the core issue here is one of depth, then the torso dor-

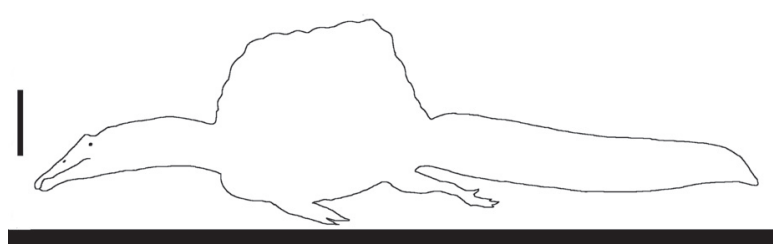

FIGURE 8. Depth of water required for Spinosaurus to avoid the considerable effects of wave drag. Even with the hind limbs lifted up, the animal is nearly $3 \mathrm{~m}$ in dorsoventral height so to avoid wave drag (fully submerged by over $3.5 \mathrm{~m}$ ) the water would need to be close to $6 \mathrm{~m}$ in depth for Spinosaurus to swim efficiently. This is a minimum and the real value is likely to be higher (see text for details). Outline modified from Ibrahim et al. (2020a) and scale bar equals $1 \mathrm{~m}$.

soventral height of $1.4 \mathrm{~m}$ (taken from figure 7 of Henderson, 2018, this value excludes the sail) is more appropriate, giving a depth of $3.5 \mathrm{~m}$. Adding the height of the body and sail of Spinosaurus (assuming the legs are retracted) of c. $2.6 \mathrm{~m}$ (based on figure 1 of Ibrahim et al., 2020a) gives an absolute minimum depth of water of at least 6.1 $\mathrm{m}$ for efficient swimming (Figure 8). On top of that, the sail itself would generate wave drag and sit within that $3.5 \mathrm{~m}$ window meaning that practically the depth would have to be even greater.

Specimens of Spinosaurus have been recovered from multiple localities and from multiple different palaeoenvironments (see the section on Environmental Factors below for further details). Although the Kem Kem at least may have consisted largely of floodplains and deltas with rare lacustrine deposits (Ibrahim et al., 2020b), Spinosaurus is also known from fluvial systems and even intertidal mangroves (Bertin, 2010). At least some of these areas are likely to be cluttered environments at, and below, the surface and with potentially limited open water and deep channels required for active pursuit predation underwater by adult spinosaurids.

Spinosaurus would be less hydrodynamic than crocodiles (higher drag), and do not have a propulsion system as efficient as them and has less tail musculature devoted to propulsion. There are therefore serious issues to be considered about the ability of Spinosaurus to swim, in particular, whether an animal the size of Spinosaurus would be capable of sufficient acceleration or agil- 
ity in water to be an effective pursuit predator, particularly given its body shape. As such, even if it could swim as well as suggested by Ibrahim et al. (2020a) it would be well below the performance of extant (and apparently extinct) pursuit predators and the data available to date does not support this model. They would also need deep water (to avoid wave drag) in which to even achieve high speeds limiting foraging areas, and then transport costs would be increased greatly as they would need to swim down and actively swim to hold this position in the water column. This would be done while still suffering from instability and buoyancy problems. It is not inconceivable that Spinosaurus might have been more agile than some swimming food items it was chasing, but such potential slow-moving food sources have not been identified. Other modes of foraging in water may still potentially be supported such as benthic prey, or burst ambush predation using a crocodile-like lunge using the tail and hind limbs. The wading model does not require swimming to be supported, but is not contradicted by the ability of Spinosaurus to swim well as it may increase the ability of them to move between areas for foraging.

\section{Dorsal and Caudal Sail Function}

The dorsal sail of Spinosaurus is widely considered to have had some role in socio-sexual display and signalling (Hone and Naish, 2013; Ibrahim et al., 2014a; Hone and Holtz, 2017). It is common for animals with socio-selected traits to have multiple signals (Hone and Naish, 2013), and indeed spinosaurids already have cranial ornamentation in addition to the elongate neural spines (Charig and Milner, 1997; Sues et al., 2002; Hone and Holtz, 2017). Elongate caudal neural spines that may have been a (socio-sexually selected) signal are seen in other dinosaurs (e.g., protoceratopsids, Tereschenko and Singer, 2013; Hone et al., 2014a). Sexually selected structures are also often highly variable within species and between closely related species (Hone and Naish, 2013), and it is notable how different the form of the dorsal spines are in Ichthyovenator (Allain et al., 2012) compared to Spinosaurus suggesting that at least one of these was not under strong selection based on their mechanical performance (cf, Hone et al., 2012).

As such, it is worth considering the possible function of the tail of Spinosaurus in terms of signalling. There are good extant analogues in the sailfin (Hydrosaurus - Denzer et al., 2020) and basilisk lizards (Basiliscus - Gilmore, 1919), which have both a dorsal crest and caudal crest that are separated at the base of the tail. Intriguingly, both swim well, but the extra tail flukes are not for improved swimming as these are typically kept clear of the water. Indeed, swimming reptilian taxa mostly do not have such 'fins' like this. As noted above, some of the more aquatically-adapted varanids ('water monitors') do have a paddle-like plate of connective tissue at the distal end of the tail (Young et al., 2008), potentially improving their swimming performance. This stiffens the distal tail, rather than increasing flexibility and there is little or no proximal dorsoventral expansion to the tail. While other forms of tail propulsion are clearly possible, water monitors would seem a useful potential model for animals that are competent terrestrially and in water with relatively large limbs and show the opposite condition of the tail to Spinosaurus, which more closely resembles those of basilisks.

Furthermore, other taxa do also show tail plumes and fins that are not linked to aquatic propulsion (e.g., drepanosaurids such as Hypuronector and Dolabrosaurus, initially interpreted as swimmers but now recognized as scansorial; Renesto et al., 2010). The tail "crest" of deep-tailed drepanosaurids match the proportions of their opposites in Spinosaurus (neural spines are shorter and the chevrons very slender and elongate in drepanosauirds, and the reverse in the theropod - Figure 9). Ibrahim et al. (2020a) also compared the performance of the tail fin of Spinosaurus to that of the male newt (Triturus cristatus). It is notable that in this species the fin is not a swimming aid but a sexually selected display feature (Green, 1991) that is absent in females (although they are more terrestrially active than males). Similarly, various crocodylians raise up their tails in water as part of their courtship displays (e.g., Garrick and Lang, 1977) so exaggerated features in the tail have an analogue in modern semiaquatic archosaurs. Finally, Persons et al. (2015) report that the elongate chevrons and reduced zygapophyses leading to increased flexion is an oviraptorosaur is potentially linked to display.

Similarly, the neural spines and the chevrons in Spinosaurus are of notably different size and constructions (Figure 9). If both were important for producing power when swimming then both might expect to be under similar selection because of the similar forces (cf. Hovasaurus, Pelamis). Instead, the chevrons are notably shorter and more robust (even distally beyond the transition point where the largest and most powerful muscles would attach). The neural spines would encounter stronger forces 


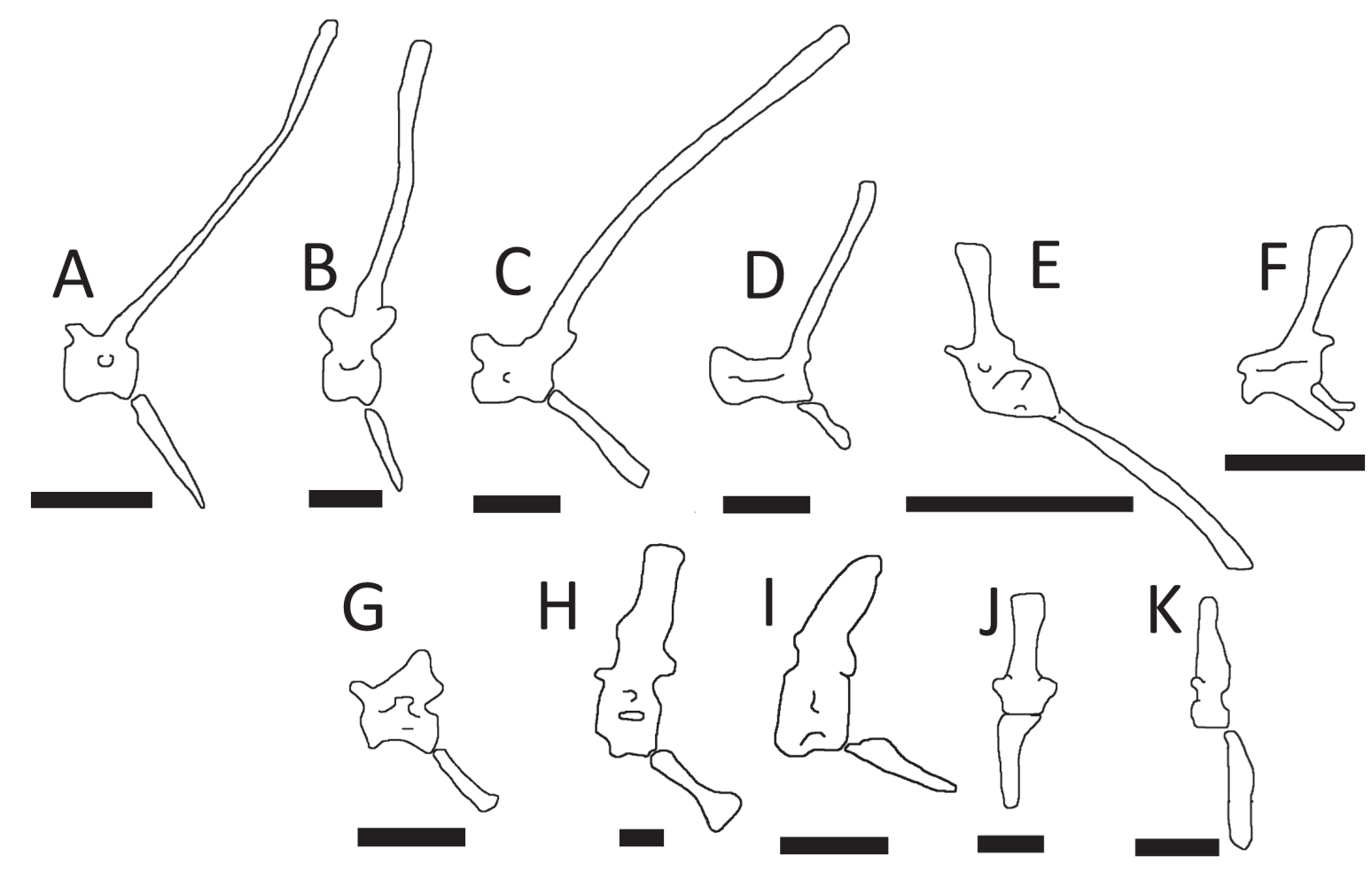

FIGURE 9. Line drawings of mid caudal vertebrae and chevrons of assorted reptiles (all in left lateral view) compared to A) Spinosaurus (Ibrahim et al., 2020a). Taxa with known or inferred signaling structures linked to their elongate neural spines (top row), B) Bagaceratops (Tereschenko and Singer, 2013), the sail-finned lizards C) Hydrosaurus* and D) Basiliscus* (courtesy of Jeroen Costeseque), E) the drepanosaur Drepanosaurus (redrawn from Sues, 2019), F) the chameleon Trioceros (courtesy of Steven Huskey), and those which show adaptations for aquatic locomotion (bottom row), G) a juvenile specimen of the crocodylian Tomistoma* (courtesy of Mathew Wedel), H) the phytosaur Mystriosuchus (Renesto and Lombardo, 1999) I) the mosasaur Mosasaurus (modified from Lindgren et al., 2011), J) the sea snake Pelamis (modified from Lindgren et al., 2011), and K) diapsid Hovasaurus* (redrawn from Sues, 2019). Scale bars are A) $200 \mathrm{~mm}$, B) $20 \mathrm{~mm}$, C) $10 \mathrm{~mm}$, D) $10 \mathrm{~mm}$, E) $20 \mathrm{~mm}$, F) $10 \mathrm{~mm}, \mathrm{G}), 20 \mathrm{~mm}, \mathrm{H}) 20 \mathrm{~mm}, \mathrm{I}) 100 \mathrm{~mm}$, J) $2 \mathrm{~mm} \mathrm{K)} 20 \mathrm{~mm}$.

than the chevrons (being longer and thus having a longer lever arm to the tip) and yet are notably thinner. Indeed, the overall shape and proportions of the midcaudal vertebrae are remarkably similar to that of the terrestrial Bagaceratops (Figure 9). Furthermore, if the tail was optimised for swimming, presumably at least on occasion the animal would be only partially submerged when in shallow water and the upper portion would be in the air and nonfunctional. An animal better optimised for swimming with a large paddle might therefore have a large ventral portion.

Thus it is possible that the caudal fin is predominantly there as a display feature and is not linked to improved aquatic propulsion, although these hypotheses are not mutually exclusive. This is consistent with other diapsids with a combination of both exaggerated dorsal and caudal sails (e.g., Hydrosaurus and Basiliscus) and some newts (e.g., Triturus). Furthermore, the absence of such a fin in many aquatic and semi-aquatic tail-sculling animals and its presence in those that do not swim (or do not use it for swimming) does not well support the pursuit predator model.

Elongate caudal neural spines may of course have had functions different from, but not mutually exclusive to, either propulsion or locomotion. For instance, as has been suggested for dorsal sails in a variety of extinct taxa, a caudal sail might serve for thermoregulation (Haack, 1986), fat storage (Bailey, 1997) or a hydrodynamic brace (Gimsa et al., 2016). The last of these seems unlikely for either the caudal or the dorsal fin, as it requires the animal to be entirely submerged; as discussed previously, there are various reasons to suspect that total submersion was not a habitual condition in Spinosaurus and a brace would likely hinder rather than benefit aquatic locomotion. The observations 
of Ibrahim et al. (2014a) that the dorsal sail was unlikely to have supported a fatty hump apply equally to the described morphology of the caudal sail. Thermoregulation, however, cannot be ruled out as a function, indeed, presence of a prominent broad surface would almost certainly change the environmental thermal exchange of an animal. That said specific modelling of the input and exchange parameters in the manner of Lovelace et al. (2020) would be needed to estimate the relative efficacy of warming vs cooling in varying degrees of submergence, a task beyond the scope of this study.

Other tall-spined and multi-tonne dinosaurs exist in different paleoenvironmental settings such as the Valanginian Hypselospinus of Great Britain (Norman, 2010) and Aptian Ouranosaurus of Niger (Bertozzo et al., 2017) among ornithopods, and the Barremian Concavenator of Spain (Ortega et al., 2010) and another spinosaurine, the Aptian Ichthyovenator of Laos (Allain et al., 2012). Thus dinosaurian sails are not restricted to the tropics of the Cenomanian-Turonian "supergreenhouse", but instead were expressed in a variety of different times and places in the Cretaceous. Of particular note, the observation that the shapes of these sails (including those of Ichthyovenator, fairly closely related to Spinosaurus) is more characteristic of a structure with a social role (such as sexually selected traits) rather than those whose properties are driven primarily by environment and physics.

\section{Environmental Factors}

The ecology of spinosaurids as a whole is clearly unusual among Mesozoic theropods, and it remains possible that Spinosaurus is unusual among the Spinosauridae or even Spinosaurinae. Despite a lack of any direct evidence for the diet of Spinosaurus, it was described by Ibrahim et al. (2014a, p1615) as "subsisting on sharks, sawfish, coelacanths, lungfish, and actinopterygians." Furthermore, Ibrahim et al. (2020a, p3) commented that the "seemingly anomalous occurrence in the same deposits of several large-bodied predators but few terrestrial herbivores is partially explained by the largely aquatic and probably piscivorous lifestyle of Spinosaurus, which considerably expands the morphological and ecological disparity of Kem Kem tetrapods. At the same time, competition with several co-occurring large aquatic predators may have driven the evolution of giant size in Spinosaurus." However, the lines of evidence available do not especially support these contentions or at least do not support pursuit predation of fish over other possibilities.

The Kem Kem beds that have yielded the best specimens of Spinosaurus are indeed unusual in their prevalence of aquatic species and numerous theropod dinosaurs but lack of herbivores, and this has been commented on repeatedly in the literature (e.g., McGowan and Dyke, 2009; Belvedere et al., 2013; Läng et al., 2013). However, there is no particular reason to think that Spinosaurus was exploiting only aquatic prey (and of that, only fish) over other available prey, or would not scavenge at least on occasion. There is an extensive record of pterosaurs in the Kem Kem, there are various terrestrial dinosaurs (theropods, ornithopods and sauropods), snakes and lizards, crocodylians, turtles (Ibrahim et al., 2020b), and there is evidence of invertebrates such as crabs (Ibrahim et al., 2014b) that all could have been taken by a large predator. Indeed, spinosaurids are known to have had an unusually broad diet based on direct evidence that includes fish, dinosaurs and pterosaurs (Allain et al., 2012).

In support of this, the calcium isotopic signatures of some Spinosaurus specimens imply a highly and possibly even exclusively piscivorous diet, but also included individuals with dinosaurs as a notable part of their diet (Hassler et al., 2018). Although overall Hassler et al. (2018) considered Spinosaurus to be more piscivorous than other theropods (and perhaps even the large contemporaneous crocodylian Sarcosuchus) they nevertheless were not exclusively piscivorous. Similarly, Amiot et al. (2010a, b) noted that while most Spinosaurus specimens have oxygen and carbon isotopic signatures suggesting a considerable amount of time was spent in water, others do not, suggesting alternation between terrestrial and aquatic ecosystems and that some spinosaurids favoured arid environments. While such behaviour is normal for some populations of modern crocodiles (Brito et al., 2011), this combination of broad diet and extensive times away from water would seem improbable for a specialised aquatic predator with reduced terrestrial capabilities as Ibrahim et al (2020a) contend. All of this is consistent with a model in which Spinosaurus derived a greater part of its diet from the aquatic realm than its sympatric theropod relatives, but nevertheless habitually also consumed terrestrial prey. This would be inconsistent with a model in which the taxon was a specialist in foraging exclusively in aquatic environments.

Specimens of Spinosaurus have been recovered from a wide variety of localities and environ- 
ments and this perhaps argues against an animal that is in some way unique in its association with the Kem Kem. Indeed, the recently suggested synonymisation of numerous genera and species within Spinosaurus aegyptiacus by Ibrahim and colleagues (Ibrahim et al., 2020b; Smyth et al., 2020) would greatly extend the temporal and geographic range of this species meaning that the oddity of the Kem Kem (which itself may be less strange that often depicted e.g., Belvedere et al., 2013) would not potentially remain an outlier and would in itself not explain the unusual morphology of Spinosaurus.

It is unclear why competition with other theropods (the extent of which is unknown) would have potentially driven the large size of Spinosaurus in the Kem Kem, or any of the other localities across North Africa where it has been recovered. Other large spinosaurines with similar anatomy are known in other localities including those that are older than Spinosaurus (e.g., pachyostotic spinosaurine in Brazil - Aureliano et al., 2018; Ichthyovenator in Laos, Allain et al., 2012), and their evolution would not have been influenced by the ecology of the Kem Kem. Since the presence of multiple large theropods (or indeed vertebrate predators generally) in environments even when exploiting similar prey is normal (Hone et al., 2010), and other spinosaurids are also large, it is not clear why such competition should drive large size in Spinosaurus in particular. Even if Spinosaurus did not exploit any terrestrial prey and solely foraged in aquatic systems, then as noted by Läng et al. (2013), they would then be competing for prey with the very large local predatory crocodilians (Sereno and Larsson, 2009; Holliday and Gardner, 2012), themselves presumably better swimmers than Spinosaurus given the results of Ibrhaim's et al.'s (2020a) tail efficiency analysis, and potentially also larger sharks and sawfish themselves. Thus if there was competition from terrestrial theropods, there must also have been competition from other aquatic predators (e.g., crocodilians, sharks, sawfish) and thus an animal potentially of exploiting both terrestrial and aquatic systems (Hone et al., 2010) where other local specialists were restricted to one, might be the better explanation.

\section{SUMMARY}

Ibrahim et al., (2020a, p3) stated that "[c]ontrary to recent suggestions that Spinosaurus was confined to wading and the apprehension of prey from around the edges of bodies of water, the morphology and function of its tail-along with its other adaptations for life in water-point to Spinosaurus having been an active and highly specialized aquatic predator that pursued and caught its prey in the water column". However, as shown here (Figure 1), there are multiple lines of evidence which do not support this contention, and none of the possible arguments would contradict the wading model.

Even good evidence for Spinosaurus being a strong swimmer would not rule out foraging from shorelines or similar lifestyles-being a good swimmer is not mutually exclusive to foraging inshore. Similarly, there are some living taxa that are moderate or even strong swimmers but either do not feed in water or are not pursuit predators (e.g., sea otters eat shellfish - Ostfeld, 1982; beavers are vegetarian - Fish and Baudinette, 1999; Dracaena eat snails - Bauer and Jackman, 2008). As a putative aquatic pursuit predator, Spinosaurus has issues with instability in water, high drag, the position of the eyes and nostrils, low swimming efficiency, strong neck ventriflexion, and isotopic signatures showing extended periods in terrestrial conditions and feeding on terrestrial animals, and there remain questions about its ability to swim and submerge effectively as a whole. If swimming to engage prey, based on the drag, performance and body shape it would be limited to lunging attack in shallow waters, not pursuit predation at speed in open water. The information provided through recent discoveries may suggest an increase in aquatic affinities for Spinosaurus, and it may have been able to swim with its tail, and even swim well compared to other theropods, but nothing presented to date contradicts the fundamentals of the 'wading model' and does not support active pursuit predation.

Spinosaurus is therefore best interpreted as shoreline generalist based on the available information. Capable of capturing both aquatic and terrestrial prey, and perhaps an opportunistic scavenger, adult Spinosaurus likely took aquatic prey by standing in shallow water or at the margins of water bodies. The nostril and eye positions, coupled with the skull shape and neck mechanics, would allow them to strike with a vertical slashing motion with the snout starting partially submerged. Standing in deeper water or even partially submerged (benefitting from reduced pneumaticity and pachyostotic bone) would allow them to forage for benthic prey or potentially lunge after faster animals. Individuals could forage in multiple different environments like this, reducing competition from 
both terrestrial and aquatic predators with an ability to use both and by being able to move between resource patches by walking or perhaps even swimming. Limited to swimming in shallow waters or to the surface of deeper water, they may have punted with limbs or used a combination of the tail and limbs together. In terms of competition, they would be able to walk between resource patches better than the crocodylians and then exploit aquatic prey better than theropods when they get there.

The ecology of a generalist Spinosaurus would have been more nuanced than the broad discussions here. Different populations would have foraged in different environments with differing faunal compositions and opportunities for predation and scavenging. In particular, juvenile animals (which would have likely lacked or had a proportionally greatly reduced dorsal sail if this was sociosexually selected) if foraging in and around water would have experienced very different levels of drag if swimming in any capacity (especially wave drag, but also simply by being smaller), would have had differing skull mechanics, and would have had different thermal characteristics to adults.

Important questions for future study remain and there is much more to be determined and for all aspects of these hypotheses to be evaluated further. While this paper focuses on Spinosaurus, many of the points raised here would also apply to other spinosaurids. It is clearly an unusual theropod, but it maintains a large amount in common anatomically and likely ecologically with other spinosaurines and baryonychines and should be con- sidered in this context. Future biomechanical examination of the performance of these taxa (in the skull, neck, forelimbs, hind limbs, and tail, and terrestrially and aquatically) will be key to understanding them.

Hypotheses for their ecology and behaviour should be based on a holistic and nuanced approach to the evidence (Hone and Faulkes, 2014), and that takes into account all of the available data and deals with conflicts and possible contradictions. This, of course, may change with further evidence and study continuing to advocate hypotheses without strong support or consideration of all of the data or alternate hypotheses should not continue. The pursuit predator model is strongly contradicted by numerous lines of evidence but by contrast the wading model is entirely consistent with the available data.

\section{ACKNOWLEDGEMENTS}

We thank C. Barker, A. Fitch, K. Formoso, M. Habib, S. Hartman, D. Henderson, G. Ugueto and $M$. Wedel for discussions on various parts of the paper. Thanks J.J. Meisenbach for the crocodile image used in Figure 7, J. Costeseque, S. Huskey and $\mathrm{M}$. Wedel for photographs used to create Figure 9 and to G. Masukawa for allowing us to use his Spinosaurus skeletal in Figures 1, 5 and 6 and $\mathrm{S}$. Hartman for the use of his Baryonyx skull in Figure 5. A. Manegold, J. Massare and A. Smith are thanked for providing copies of papers. We thank three anonymous referees, S. Evers and the editor for comments which improved this manuscript.

\section{REFERENCES}

Alexander, R.M. 2003. Principles of Animal Locomotion. Princeton University Press, Princeton.

Allain, R., Xaisanavong, T., Richir, P., and Khentavong, B. 2012. The first definitive Asian spinosaurid (Dinosauria: Theropoda) from the Early Cretaceous of Laos. Naturwissenschaften, 99:369-377. https://doi.org/10.1007/s00114-012-0911-7

Amiot, R., Buffetaut, E., Lecuyer, C., Wang, X., Boudad, L., Ding, Z., Fourel, F., Hutt, S., Martineau, F., Medeiros, M.A., Mo, J., Simon, L., Suteethorn, V., Sweetman, S., Tong, H., Zhang, F., and Zhou, Z. 2010a. Oxygen isotope evidence for semi-aquatic habits among spinosaurid theropods. Geology, 38:139-142. https://doi.org/10.1130/g30402.1

Amiot, R., Wang, X., Lécuyer, C., Buffetaut, E., Boudad, L., Cavin, L., Ding, Z., Fluteau, F., Kellner, A.W., Tong, H., and Zhang, F. 2010b. Oxygen and carbon isotope compositions of middle Cretaceous vertebrates from North Africa and Brazil: Ecological and environmental significance. Palaeogeography, Palaeoclimatology, Palaeoecology, 297:439-451.

https://doi.org/10.1016/j.palaeo.2010.08.027 
Arden, T.M., Klein, C.G., Zouhri, S., and Longrich, N.R. 2019. Aquatic adaptation in the skull of carnivorous dinosaurs (Theropoda: Spinosauridae) and the evolution of aquatic habits in spinosaurids. Cretaceous Research, 93:275-284. https://doi.org/10.1016/j.cretres.2018.06.013

Aureliano, T., Ghilardi, A.M., Buck, P.V., Fabbri, M., Samathi, A., Delcourt, R., Fernandes, M.A., and Sander, M. 2018. Semi-aquatic adaptations in a spinosaur from the Lower Cretaceous of Brazil. Cretaceous Research, 90:283-295. https://doi.org/10.1016/j.cretres.2018.04.024

Bailey, J.B. 1997. Neural spine elongation in dinosaurs: sailbacks or buffalo-backs? Journal of Paleontology, 71:1124-1146. https://doi.org/10.1017/s0022336000036076

Barker, C.T., Naish, D., Newham, E., Katsamenis, O.L., and Dyke, G. 2017. Complex neuroanatomy in the rostrum of the Isle of Wight theropod Neovenator salerii. Scientific Reports, 7:1-8. https://doi.org/10.1038/s41598-017-03671-3

Bauer, A.M. and Jackman, T. 2008. Global diversity of lizards in freshwater (Reptilia: Lacertilia). Hydrobiologia, 595:581-586. https://doi.org/10.1007/s10750-007-9115-0

Beevor, T., Quigley, A., Smith, R.E., Smyth, R.S., Ibrahim, N., Zouhri, S., and Martill, D.M., 2020. Taphonomic evidence supports an aquatic lifestyle for Spinosaurus. Cretaceous Research, 117:104627. https://doi.org/10.1016/j.cretres.2020.104627

Belvedere, M., Jalil, N.E., Breda, A., Gattolin, G., Bourget, H., Khaldoune, F., and Dyke, G.J. 2013. Vertebrate footprints from the Kem Kem beds (Morocco): a novel ichnological approach to faunal reconstruction. Palaeogeography, Palaeoclimatology, Palaeoecology, 383:52-58. https://doi.org/10.1016/j.palaeo.2013.04.026

Bertin, T. 2010. A catalogue of material and review of the Spinosauridae. PalArch's Journal of Vertebrate Palaeontology, 7:1-39.

Bertozzo, F., Dalla Vechia, F.M., and Fabbri, M. 2017. The Venice specimen of Ouranosaurus nigeriensis (Dinosauria, Ornithopoda). PeerJ, 5:e3403. https://doi.org/10.7717/peerj.3403

Birn-Jeffery, A.V., Miller, C.E., Naish, D., Rayfield, E.J., and Hone, D.W.E. 2012. Pedal claw curvature in birds, lizards and Mesozoic dinosaurs-complicated categories and compensating for mass-specific and phylogenetic control. PLoS One, 7:p.e50555. https://doi.org/10.1371/journal.pone.0050555

Brito, J.C., Martínez-Freiría, F., Sierra, P., Sillero, N., and Tarroso, P. 2011. Crocodiles in the Sahara Desert: an update of distribution, habitats and population status for conservation planning in Mauritania. PLoS one, 6:14734. https://doi.org/10.1371/journal.pone.0014734

Bro-Jørgensen, J. 2013. Evolution of sprint speed in African savannah herbivores in relation to predation. Evolution, 67(11):3371-3376. https://doi.org/10.1111/evo.12233

Buchholtz, E.A. 2001a. Swimming styles in Jurassic ichthyosaurs. Journal of Vertebrate Paleontology, 21:61-73. https://doi.org/10.1671/0272-4634(2001)021[0061:ssiji]2.0.co;2

Buchholtz, E.A. 2001b. Vertebral osteology and swimming style in living and fossil whales (Order Cetacea). Journal of Zoology, 253:175-190. https://doi.org/10.1017/s0952836901000164

Buffetaut, E. 2012. An early spinosaurid dinosaur from the Late Jurassic of Tendaguru (Tanzania) and the evolution of the spinosaurid dentition. Oryctos, 10:1-8.

Carr, T.D., Varricchio, D.J., Sedlmayr, J.C., Roberts, E.M., and Moore, J.R. 2017. A new tyrannosaur with evidence for anagenesis and crocodile-like facial sensory system. Scientific Reports, 7:44942. https://doi.org/10.1038/srep44942

Cau, A. 2020. The body plan of Halszkaraptor escuilliei (Dinosauria, Theropoda) is not a transitional form along the evolution of dromaeosaurid hypercarnivory. PeerJ, 8:p.e8672. https://doi.org/10.7717/peerj.8672

Charig, A.J. and Milner, A.C. 1997. Baryonyx walkeri, a fish-eating dinosaur from the Wealden of Surrey. Bulletin of the Natural History Museum Geology, 53:11-70.

Chatterjee, S. 1978. A primitive Parasuchid (Phytosaur) reptile from upper Triassic. Palaeontology, 21(1):83-127.

Cresswell, W. and Quinn, J.L. 2013. Contrasting risks from different predators change the overall nonlethal effects of predation risk. Behavioral Ecology, 24:871-876. https://doi.org/10.1093/beheco/art023

Cuff, A.R. and Rayfield, E.J. 2013. Feeding mechanics in spinosaurid theropods and extant crocodilians. PLoS One, 8:e65295. https://doi.org/10.1371/journal.pone.0065295

Dal Sasso, C., Maganuco, S., Buffetaut, E., and Mendez, M. 2005. New information on the skull of the enigmatic theropod Spinosaurus, with remarks on its size and affinities. Journal of Vertebrate Paleontology, 25:888-896. https://doi.org/10.1671/0272-4634(2005)025[0888:NIOTSO]2.0.CO;2 
Davenport, J. and Sayer, M.J. 1989. Observations on the aquatic locomotion of young salt-water crocodiles (Crocodylus porosus Schneider). Herpetological Journal, 1:356-361.

Demarco, P.N., Meneghel, M., Laurin, M., and Piñeiro, G. 2018. Was Mesosaurus a fully aquatic reptile? Frontiers in Ecology and Evolution, 6:109. https://doi.org/10.3389/fevo.2018.00109

Denzer, W., Campbell, P.D., Manthey, U., Glässer-Trobisch, A., and Koch, A. 2020. Dragons in neglect: taxonomic revision of the Sulawesi sailfin lizards of the genus Hydrosaurus Kaup, 1828 (Squamata, Agamidae). Zootaxa, 4747:275-301. https://doi.org/10.11646/zootaxa.4747.2.3

Erickson, G.M., Gignac, P.M., Steppan, S.J., Lappin, A.K., Vliet, K.A., Brueggen, J.D., Inouye, B.D., Kledzik, D., and Webb, G.J. 2012. Insights into the ecology and evolutionary success of crocodilians revealed through bite-force and tooth-pressure experimentation. PLoS One, 7:e31781. https://doi.org/10.1371/journal.pone.0031781

Evers, S.W., Rauhut, O.W., Milner, A.C., McFeeters, B., and Allain, R. 2015. A reappraisal of the morphology and systematic position of the theropod dinosaur Sigilmassasaurus from the "middle" Cretaceous of Morocco. PeerJ, 3:1323. https://doi.org/10.7717/peerj.1323

Fanti, F., Cau, A., Martinelli, A. and Contessi, M., 2014. Integrating palaeoecology and morphology in theropod diversity estimation: a case from the Aptian-Albian of Tunisia. Palaeogeography, Palaeoclimatology, Palaeoecology, 410:39-57. https://doi.org/10.1016/j.palaeo.2014.05.033

Fish, F.E. 1984. Kinematics of undulatory swimming in the American alligator. Copeia, 1984:839843. https://doi.org/10.2307/1445326

Fish, F.E. and Baudinette, R.V. 1999. Energetics of locomotion by the Australian water rat (Hydromys chrysogaster): a comparison of swimming and running in a semi-aquatic mammal. Journal of Experimental Biology, 202:353-363.

Fish, F.E. 2016. Secondary evolution of aquatic propulsion in higher vertebrates: validation and prospect. Integrative and Comparative Biology, 56:1285-1297. https://doi.org/10.1093/icb/icw123

Frey, E. 1982. Ecology, locomotion and tail muscle anatomy of crocodiles. Neues Jahrbuch für Geologie und Paläontologie-Abhandlungen, 164:194-199.

Gao, K., Evans, S., Qiang, J., Norell, M., and Shu'An, J. 2000. Exceptional fossil material of a semi-aquatic reptile from China: the resolution of an enigma. Journal of Vertebrate Paleontology, 20:417-421. https://doi.org/10.1671/0272-4634(2000)020[0417:efmoas]2.0.co;2

Garrick, L.D. and Lang, J.W. 1977. Social signals and behaviors of adult alligators and crocodiles. American Zoologist, 17:225-239. https://doi.org/10.1093/icb/17.1.225

Gilmore, C.W. 1919. A mounted skeleton of Dimetrodon gigas in the United States National Museum, with notes on the skeletal anatomy. Proceedings of the United States National Museum, 56:525-539. https://doi.org/10.5479/SI.00963801.56-2300.525

Gimsa, J., Sleigh, R., and Gimsa, U. 2016. The riddle of Spinosaurus aegyptiacus' dorsal sail. Geological Magazine, 153:544-547. https://doi.org/10.1017/s0016756815000801

Haack, S.C. 1986. A thermal model of the sailback pelycosaur. Paleobiology, 12:450-458. https://doi.org/10.1017/s009483730000316x

Hammer, Ø., Harper, D.A.T., and P.D. Ryan. 2001. PAST: Paleontological Statistics Software Package for Education and Data Analysis. Palaeontologia Electronica 4.1.4A:1-9. https://palaeo-electronica.org/2001_1/past/issue1_01.htm Version 4.03 (2020). Available from https://folk.uio.no/ohammeer/past [Accessed 13 September 2020].

Hanson, J.O., Salisbury, S.W., Campbell, H.A., Dwyer, R.G., Jardine, T.D., and Franklin, C.E. 2015. Feeding across the food web: The interaction between diet, movement and body size in estuarine crocodiles (Crocodylus porosus). Austral Ecology, 40:275-286. https://doi.org/10.1111/aec.12212

Hassler, A. Martin, J. E., Amiot, R., Tacail, T., Arnaud Godet, F., Allain, R., and Balter, V. 2018. Calcium isotopes offer clues on resource partitioning among Cretaceous predatory dinosaurs. Proceedings of the Royal Society B: Biological Sciences, 285:20180197. https://doi.org/10.1098/rspb.2018.0197

Heckeberg, N.S. and Rauhut, O.W.M. 2020. Histology of spinosaurid dinosaur teeth from the Albian-Cenomanian of Morocco: implications for tooth replacement and ecology. Palaeontologia Electronica, 23(3):a48. https://doi.org/10.26879/1041 
Henderson, D.M. 2018. A buoyancy, balance and stability challenge to the hypothesis of a semiaquatic Spinosaurus Stromer, 1915 (Dinosauria: Theropoda). PeerJ, 6:e5409. https://doi.org/10.7717/peerj.5409

Hendrickx, C., Mateus, O., and Buffetaut, E. 2016. Morphofunctional analysis of the quadrate of Spinosauridae (Dinosauria: Theropoda) and the presence of Spinosaurus and a second spinosaurine taxon in the Cenomanian of North Africa. PLoS One, 11:e0144695. https://doi.org/10.1371/journal.pone.0144695

Heyning, J.E. and Mead, J.G. 1990. Evolution of the nasal anatomy of cetaceans, p. 67-79. In Thomas, J. and Kastelein, R. (eds.), Sensory Abilities of Cetaceans. Springer, Boston, Massachusetts.

Hildebrand, M. 1996. Analysis of Vertebrate Structure. John Wiley, London.

Holliday, C.M. and Gardner, N.M. 2012. A new eusuchian crocodyliform with novel cranial integument and its significance for the origin and evolution of Crocodylia. PLoS One, 7:e30471. https://doi.org/10.1371/journal.pone.0030471

Holtz, T.R., Jr. 1998. Spinosaurs as crocodile mimics. Science, 282:1276-1277. https://doi.org/10.1126/science.282.5392.1276

Holtz, T.R., Jr., Molnar, R.E., and Currie, P.J. 2004. Basal Tetanurae, p. 71-110. In Weishampel, D.B., Dodson, P., and Osmólska, H. (eds.), The Dinosauria. University of California Press, Berkley. https://doi.org/10.1525/california/9780520242098.003.0006

Hone, D.W.E., Xu, X., and Wang, D.Y. 2010. A probable baryonychine (Theropoda: Spinosauridae) tooth from the Upper Cretaceous of Henan Province, China. Vertebrata PalAsiatica, 48:19-26.

Hone, D.W.E., Naish, D., and Cuthill, I.C. 2012. Does mutual sexual selection explain the evolution of head crests in pterosaurs and dinosaurs? Lethaia, 45:139-156. https://doi.org/10.1111/j.1502-3931.2011.00300.x

Hone, D.W.E. and Naish, D. 2013. The 'species recognition hypothesis' does not explain the presence and evolution of exaggerated structures in non-avialan dinosaurs. Journal of Zoology, 290:172-180. https://doi.org/10.1111/jzo.12035

Hone, D.W.E. and Faulkes, C.J. 2014. A proposed framework for establishing and evaluating hypotheses about the behaviour of extinct organisms. Journal of Zoology, 292:260-267. https://doi.org/10.1111/jzo.12114

Hone, D.W., Wood, D., and Knell, R.J. 2016. Positive allometry for exaggerated structures in the ceratopsian dinosaur Protoceratops andrewsi supports socio-sexual signaling. Palaeontologia Electronica, 19.1.5A:1-13. https://doi.org/10.26879/591

Hone, D.W.E. and Holtz, Jr, T.R. 2017. A century of spinosaurs?a review and revision of the Spinosauridae with comments on their ecology. Acta Geologica Sinica?English Edition, 93:1120-1132. https://doi.org/10.1111/1755-6724.13328

Hone, D.W.E. and Holtz, Jr, T.R. 2019. Comment on: Aquatic adaptation in the skull of carnivorous dinosaurs (Theropoda: Spinosauridae) and the evolution of aquatic habits in spinosaurids. Cretaceous Research, 104152. https://doi.org/10.1016/j.cretres.2019.05.010

Houssaye, A. 2009. "Pachyostosis" in aquatic amniotes: a review. Integrative Zoology, 4:325340. https://doi.org/10.1111/j.1749-4877.2009.00146.x

Ibrahim, N., Sereno, P.C., Dal Sasso, C., Maganuco, S., Fabbri, M., Martill, D.M., Zouhri, S., Myhrvold, N., and lurino, D.A. 2014. Semiaquatic adaptations in a giant predatory dinosaur. Science, 345:1613-1616. https://doi.org/10.1126/science.1258750

Ibrahim, N., Varricchio, D.J., Sereno, P.C., Wilson, J.A., Dutheil, D.B., Martill, D.M., Baidder, L., and Zouhri, S. 2014. Dinosaur footprints and other ichnofauna from the Cretaceous Kem Kem Beds of Morocco. PLoS One, 9:p.e90751. https://doi.org/10.1371/journal.pone.0090751

Ibrahim, N., Maganuco, S., Dal Sasso, C., Fabbri, M., Auditore, M., Bindellini, G., Martill, D.M., Zouhri, S., Mattarelli, D.A., Unwin, D.M., and Wiemann, J. 2020a. Tail-propelled aquatic locomotion in a theropod dinosaur. Nature, 581:67-70. https://doi.org/10.1038/s41586-020-2190-3

Ibrahim, N., Sereno, P.C., Varricchio, D.J., Martill, D.M., Dutheil, D.B., Unwin, D.M., Baidder, L., Larsson, H.C., Zouhri, S., and Kaoukaya, A. 2020b. Geology and paleontology of the Upper Cretaceous Kem Kem Group of eastern Morocco. ZooKeys, 928:1.

Johnson, M.M., Young, M.T., and Brusatte, S.L. 2020. The phylogenetics of Teleosauroidea (Crocodylomorpha, Thalattosuchia) and implications for their ecology and evolution. PeerJ, 8:e9808. https://doi.org/10.7717/peerj.9808

Kushlan, J.A. 1976. Feeding behavior of North American herons. The Auk, 93:86-94. 
Läng, E., Boudad, L., Maio, L., Samankassou, E., Tabouelle, J., Tong, H., and Cavin, L. 2013. Unbalanced food web in a Late Cretaceous dinosaur assemblage. Palaeogeography, Palaeoclimatology, Palaeoecology, 381:26-32. https://doi.org/10.1016/j.palaeo.2013.04.011

Lindgren, J., Jagt, J.W.M., and Caldwell, M.W. 2007. A fishy mosasaur: the axial skeleton of Plotosaurus (Reptilia, Squamata) reassessed. Leithaia, 40:153-160. https://doi.org/10.1111/j.1502-3931.2007.00009.x

Lindgren, J., Polcyn, M.J., and Young, B.A. 2011. Landlubbers to leviathans: evolution of swimming in mosasaurine mosasaurs. Paleobiology, 37:445-469. https://doi.org/10.1666/09023.1

Lingham-Soliar, T. 1991. Locomotion in mosasaurs. Modern Geology, 16:229-248.

Lovelace, D.M., Hartman, S.A., Mathewson, P.D., Linzmeier, B.J., and Porter, W.P. 2020. Modeling dragons: using linked mechanistic physiological and microclimate models to explore environmental, physiological, and morphological constraints on the early evolution of dinosaurs. PLoS One, 15: e0223872. https://doi.org/10.1101/790980

Manegold, A. 2006. Two additional synapomorphies of grebes Podicipedidae and flamingos Phoenicopteridae. Acta Ornithologica, 41:79-82. https://doi.org/10.3161/068.041.0113

Massare, J.A. 1987. Tooth morphology and prey preference of Mesozoic marine reptiles. Journal of Vertebrate Paleontology, 7:121-137. https://doi.org/10.1080/02724634.1987.10011647

Massare, J.A. 1988. Swimming capabilities of Mesozoic marine reptiles: implications for method of predation. Paleobiology, 14:187-205. https://doi.org/10.1017/s009483730001191x

Massare, J.A. 1994. Swimming capabilities of Mesozoic marine reptiles, p. 113-150. In Maddock, L., Bone, Q., and Rayner, J.M.V. (eds.), The Mechanics and Physiology of Animal Swimming. Cambridge University Press, Cambridge. https://doi.org/10.1017/cbo9780511983641.011

McCurry, M.R., Evans, A.R., Fitzgerald, E.M., McHenry, C.R., Bevitt, J., and Pyenson, N.D. 2019. The repeated evolution of dental apicobasal ridges in aquatic-feeding mammals and reptiles. Biological Journal of the Linnean Society, 127:245-259. https://doi.org/10.1093/biolinnean/blz025

McGowan, A.J. and Dyke, G.J. 2009. A surfeit of theropods in the Moroccan Late Cretaceous? Comparing diversity estimates from field data and fossil shops. Geology, 37:843-846. https://doi.org/10.1130/g30188a.1

McHenry, C.R., Clausen, P.D., Daniel, W.J.T., Meers, M.B., and Pendharkar, A. 2006. Biomechanics of the rostrum in crocodilians: a comparative analysis using finite-element modeling. The Anatomical Record, 288A:827-849. https://doi.org/10.1002/ar.a.20360

Molnar, J.L., Pierce, S.E., Bhullar, B.A.S., Turner, A.H., and Hutchinson, J.R. 2015. Morphological and functional changes in the vertebral column with increasing aquatic adaptation in crocodylomorphs. Royal Society Open Science, 2:150439. https://doi.org/10.1098/rsos.150439

Norman, D.B. 2010. A taxonomy of iguanodontians (Dinosauria: Ornithopoda) from the lower Wealden Group (Cretaceous: Valanginian) of southern England. Zootaxa, 2489:47-66. https://doi.org/10.11646/zootaxa.2489.1.3

Ortega, F., Escaso, F., and Sanz, J.L. 2010. A bizarre, humped Carcharodontosauria (Theropoda) from the Lower Cretaceous of Spain. Nature, 467:203-206. https://doi.org/10.1038/nature09181

Ostfeld, R.S. 1982. Foraging strategies and prey switching in the California sea otter. Oecologia, 53:170-178. https://doi.org/10.1007/bf00545660

Paul, G.S. 1988. Predatory Dinosaurs of the World. The New York Academy of Sciences, New York.

Persons, IV, W.S., Funston, G.F., Currie, P.J., and Norell, M.A. 2015. A possible instance of sexual dimorphism in the tails of two oviraptorosaur dinosaurs. Scientific Reports, 5:1-4. https://doi.org/10.1038/srep09472

Pierce, S.E., Angielczyk, K.D., and Rayfield, E.J. 2008. Patterns of morphospace occupation and mechanical performance in extant crocodilian skulls: a combined geometric and finite element modeling approach. Journal of Morphology, 269:840-864. https://doi.org/10.1002/jmor.10627

Pierce, S.E., Angielczyk, K.D., and Rayfield, E.J. 2009. Shape and mechanics in thalattosuchian (Crocodylomorpha) skulls: implications for feeding behaviour and niche partitioning. Journal of Anatomy, 15:555-576. https://doi.org/10.1111/j.1469-7580.2009.01137.x 
Porter, W.M.R. and Witmer, L.M. 2020. Vascular patterns in the heads of dinosaurs: evidence for blood vessels, sites of thermal exchange, and their role in physiological thermoregulatory strategies. The Anatomical Record, 303:1075-1103. https://doi.org/10.1002/ar.24234

Rayfield, E., Milner, A.C., Xuan, V.B., and Young, P.G. 2007. Functional morphology of spinosaur 'crocodile mimic' dinosaurs. Journal of Vertebrate Paleontology, 27:892-901. https://doi.org/10.1671/0272-4634(2007)27[892:fmoscd]2.0.co;2

Renesto, S. and Lombardo, C. 1999. Structure of the tail of a phytosaur (Reptilia, Archosauria) from the Norian (Late Triassic) of Lombardy (Northern Italy). Rivista Italiana di Paleontologia e Stratigrafia, 105:135-144. https://doi.org/10.13130/2039-4942/5368

Renesto, S., Spielmann, J.A., Lucas, S.G., and Spagnoli, G.T. 2010. The taxonomy and paleobiology of the Late Triassic (Carnian-Norian: Adamanian-Apachean) drepanosaurs (Diapsida: Archosauromorpha: Drepanosauromorpha). New Mexico Museum of Natural History and Science, Albuquerque, 81.

Ringma, J.L. and Salisbury, S.W. 2014. Aquatic locomotor kinematics of the eastern water dragon (Intellagama lesueurii). Journal of Herpetology, 48:240-248. https://doi.org/10.1670/12-041

Sales, M.A. and Schultz, C.L. 2017. Spinosaur taxonomy and evolution of craniodental features: evidence from Brazil. PLoS One, 12:0187070. https://doi.org/10.1371/journal.pone.0187070

Sailsbury, S.W. and Frey, E. 2001. A biomechanical transformation model for the evolution of semi-spheroidal articulations between adjoining vertebral bodies in crocodilians, p. 85-134. In Grigg, G., Seebacher, F., and Franklin, C. (eds.), Crocodilian Biology and Evolution. Surrey Beatty and Sons, Chipping Norton.

Sander, P.M. 2000. Ichthyosauria: their diversity, distribution, and phylogeny. Paläontologische Zeitschrift, 74:1-35.

Schade, M., Rauhut, O.W., and Evers, S.W. 2020. Neuroanatomy of the spinosaurid Irritator challengeri (Dinosauria: Theropoda) indicates potential adaptations for piscivory. Scientific Reports, 10:1-9. https://doi.org/10.1038/s41598-020-66261-w

Schwarz-Wings, D., Frey, E., and Martin, T. 2009. Reconstruction of the bracing system of the trunk and tail in hyposaurine dyrosaurids (Crocodylomorpha; Mesoeucrocodylia). Journal of Vertebrate Paleontology, 29:453-372. https://doi.org/10.1671/039.029.0228

Seebacher, F., Elsworth, P.G., and Franklin, C.E. 2003. Ontogenetic changes of swimming kinematics in a semi-aquatic reptile (Crocodylus porosus). Australian Journal of Zoology, 51:15-24. https://doi.org/10.1071/zo02036

Sereno, P.C., Beck, A.L., Dutheil, D.B., Gado, B., Larsson, H.C., Lyon, G.H., Marcot, J.D., Rauhut, O.W., Sadleir, R.W., Sidor, C.A., and Varricchio, D.D. 1998. A long-snouted predatory dinosaur from Africa and the evolution of spinosaurids. Science, 282:1298-1302. https://doi.org/10.1126/science.282.5392.1298

Sereno, P. and Larsson, H. 2009. Cretaceous crocodyliforms from the Sahara. ZooKeys, 28:1. https://doi.org/10.3897/zookeys.28.325

Smith, J.B., Lamanna, M.C., Mayr, H., and Lacovara, K.J. 2006. New information regarding the holotypeof Spinosaurus aegyptiacus Stromer, 1915.JournalofPaleontology,80:400-406. https://doi.org/10.1666/0022-3360(2006)080[0400:nirtho]2.0.co;2

Smyth, R.S., Ibrahim, N., and Martill, D.M. 2020. Sigilmassasaurus is Spinosaurus: a reappraisal of African spinosaurines. Cretaceous Research, 114:104520. https://doi.org/10.1016/j.cretres.2020.104520

Spiekman, S.N., Neenan, J.M., Fraser, N.C., Fernandez, V., Rieppel, O., Nosotti, S., and Scheyer, T.M. 2020. Aquatic habits and niche partitioning in the extraordinarily long-necked Triassic reptile Tanystropheus. Current Biology, 30(19):3889-3895. https://doi.org/10.1016/j.cub.2020.07.025

Stocker, M.R. and Butler, R.J. 2013. Phytosauria. p. 91-117. In Nesbitt, S.J., Desojo, J.B., and Irmis, R.B. (eds.), Anatomy, Phylogeny and Palaeobiology of Early Archosaurs and Their Kin. Geological Society of London, London.

Stocker, M.R., Zhao, L.-J., Nesbitt, S.J., Wu, X.-C., and Li, C. 2017. A short-snouted, Middle Triassic phytosaur and its implications for the morphological evolution and biogeography of Phytosauria. Scientific Reports, 7:46028. https://doi.org/10.1038/srep46028

Stromer, E. 1915. Das original des theropoden Spinosaurus aegyptiacus nov. gen., nov. spec. Königlich Bayerische Akademie der Wissenschaften.

Sues, H.D. 2019. The Rise of Reptiles: 320 Million Years of Evolution. John Hopkins University Press, Baltimore. 
Sues, H.D., Frey, E., Martill, D.M., and Scott, D.M. 2002. Irritator challengeri, a spinosaurid (Dinosauria: Theropoda) from the Lower Cretaceous of Brazil. Journal of Vertebrate Paleontology, 22:535-547. https://doi.org/10.1671/0272-4634(2002)022[0535:icasdt]2.0.co;2

Taylor, M.P. and Wedel, M.J. 2013. Why sauropods had long necks; and why giraffes have short necks. PeerJ, 1:36. https://doi.org/10.7717/peerj.36

Tereschenko, V.S. and Singer, T. 2013. Structural features of neural spines of the caudal vertebrae of protoceratopoids (Ornithischia: Neoceratopsia). Paleontological Journal, 47:618-630. https://doi.org/10.1134/s0031030113060105

Thewissen, J.G. and Fish, F.E. 1997. Locomotor evolution in the earliest cetaceans: functional model, modern analogues, and paleontological evidence. Paleobiology, 23:482-490. https://doi.org/10.1017/s0094837300019850

Tinius, A. and Patrick Russell, A. 2017. Points on the curve: an analysis of methods for assessing the shape of vertebrate claws. Journal of Morphology, 278:150-169. https://doi.org/10.1002/jmor.20625

Villamil, J., Demarco, P.N., Meneghel, M., Blanco, R.E., Jones, W., Rinderknecht, A., Laurin, M., and Piñeiro, G. 2016. Optimal swimming speed estimates in the Early Permian mesosaurid Mesosaurus tenuidens (Gervais 1865) from Uruguay. Historical Biology, 28:963-971. https://doi.org/10.1080/08912963.2015.1075018

Volpov, B.L., Hoskins, A.J., Battaile, B.C., Viviant, M., Wheatley, K.E., Marshall, G., Abernathy, K., and Arnould, J.P. 2015. Identification of prey captures in Australian fur seals (Arctocephalus pusillus doriferus) using head-mounted accelerometers: field validation with animal-borne video cameras. PLoS One, 10:p.e0128789. https://doi.org/10.1371/journal.pone.0128789

Vullo, R., Allain, R., and Cavin, L. 2016. Convergent evolution of jaws between spinosaurid dinosaurs and pike conger eels. Acta Palaeontologica Polonica, 61:825-828. https://doi.org/10.4202/app.00284.2016

Webb, P.W. and De Buffrénil, V. 1990. Locomotion in the biology of large aquatic vertebrates. Transactions of the American Fisheries Society, 119:629-641. https://doi.org/10.1577/1548-8659(1990)119<0629:LITBOL>2.3.CO;2

Weihs, D. and Webb, P.W. 1983. Optimization of locomotion, p. 339-371. In Webb, P.W. and Weihs, D. (eds.), Fish Biomechanics. Praeger Press, New York.

Whitaker, R. and Basu, D. 1983. The gharial (Gavialis gangeticus): a review. Journal of the Bombay Natural History Society, 79:531-548.

Young, B.A., Boetig, M., Fahey, A., and Lawrence, A. 2008. The diversity of aquatic locomotion in extant varanoid lizards. Fort Hayes Studies Special Issues, 3:159-167. 


\section{APPENDIX 1.}

Table of data used in the analyses presented in Figures 2, 3 and 4. Includes all measurements and sources. Table supplied in zipped format at https://palaeo-electronica.org/content/2021/ 3219-the-ecology-of-spinosaurus 